\title{
Possibilidades de incorporação da análise crítica do discurso de Norman Fairclough no estudo das organizações
}

\author{
EVERTON RODRIGUES DA SILVA \\ Universidade Federal de Alfenas / InStituto de Ciências Sociais Aplicadas, CAMpus VARGinha, VARgINHA - MG, BRASIL \\ Carlos Alberto Gonçalves \\ Universidade federal de Minas Gerais / Faculdade de CiÊnCIAS ECONÔMICAS, Belo Horizonte - MG, BrasiL \\ UNIVERSIDADE FUMEC, BELO HORIZONTE - MG, BRASIL
}

\begin{abstract}
Resumo
Partimos de uma lacuna epistemológica em trabalhos sobre a análise de discurso aplicada à gestão para apresentar possibilidades de incorporação nos estudos organizacionais da análise crítica do discurso (ACD) de Norman Fairclough. A ACD compreende as organizações como formações ideológico-discursivas, trazendo à tona a relação entre ideologia, hegemonia e discurso. Suscitamos, em verdade, uma ponderação sobre o objeto e método de trabalho do pesquisador em administração. A proposta de Fairclough é claramente uma alternativa nessa direção, pois possibilita uma reflexão onto-epistemológica sobre as organizações combinada a um esforço metodológico, que termina por sugerir alternativas de pesquisa sobre a emergência, hegemonia, recontextualização e operacionalização discursiva no cotidiano organizacional. Por fim, acreditamos que a ACD cumpre a função de não separar os discursos de um campo particular que se supõe autônomo - como uma corporação - de seu contexto social, o que possibilita uma interpretação crítica das organizações - descolada dos saberes reificados sobre a gestão - e uma reconexão da administração às problemáticas contemporâneas da sociedade.
\end{abstract}

Palavras-chave: Discurso. Ideologia. Análise crítica do discurso. Norman Fairclough. Organizações.

\section{Possibilities of incorporating Norman Fairclough's critical discourse analysis into the study of organizations}

\begin{abstract}
We start from an epistemological gap in papers on discourse analysis applied to management to introduce possibilities of incorporating Norman Fairclough's critical discourse analysis (CDA) into organizational studies. CDA sees organizations as ideological and discursive formations, bringing up the relation between ideology, hegemony, and discourse. In fact, we give rise to reflection on the administration researcher's object and working method. Fairclough's proposal is clearly an alternative in this direction, as it enables an onto-epistemological reflection on organizations combined to a methodological effort, which ends up suggesting research alternatives on the emergence, hegemony, recontextualization, and discursive operation in the organizational routine. Finally, we believe that CDA plays the role of not separating the discourses of a particular field that is supposedly autonomous - such as a corporation - from their social context, something which enables a critical interpretation of organizations - detached from reified knowledge on management - and a reconnection of administration to the issues of contemporary society.
\end{abstract}

Keywords: Discourse. Ideology. Critical discourse analysis. Norman Fairclough. Organizations.

\section{Posibilidades de incorporación del análisis crítico del discurso de Norman Fairclough en el estudio de las organizaciones}

\section{Resumen}

Partimos de una brecha epistemológica en los trabajos sobre el análisis del discurso relacionado a la gestión para presentar posibilidades de incorporación en los estudios organizacionales del análisis crítico del discurso (ACD) de Norman Fairclough. El ACD comprende las organizaciones como formaciones ideológico-discursivas, poniendo en evidencia la relación entre ideología, hegemonía y discurso. Planteamos, en realidad, una reflexión sobre el objeto y el método de trabajo del investigador en administración. La propuesta de Fairclough es, claramente, una alternativa en ese sentido, pues permite una reflexión onto-epistemológica sobre las organizaciones, combinada con el esfuerzo metodológico, lo que sugiere alternativas de investigación acerca de la emergencia, hegemonía, recontextualización y operacionalización discursiva en la vida cotidiana de la organización. Por último, consideramos que el ACD cumple la función de no separar los discursos de un campo en particular que se supone autónomo-como una corporación- de su contexto social, lo que permite una interpretación crítica de las organizaciones-independiente del conocimiento cosificado acerca de la gestión- y una reconexión de la administración con los problemas de la sociedad contemporánea.

Palabras clave: Discurso. Ideología. Análisis crítico del discurso. Norman Fairclough. Organizaciones.

Artigo submetido em 19 de agosto de 2014 e aceito para publicação em 20 de fevereiro de 2015.

Os autores agradecem as contribuições dos avaliadores por considerá-las fundamentais para a elaboração do artigo.

DOI: http://dx.doi.org/10.1590/1679-395132088 


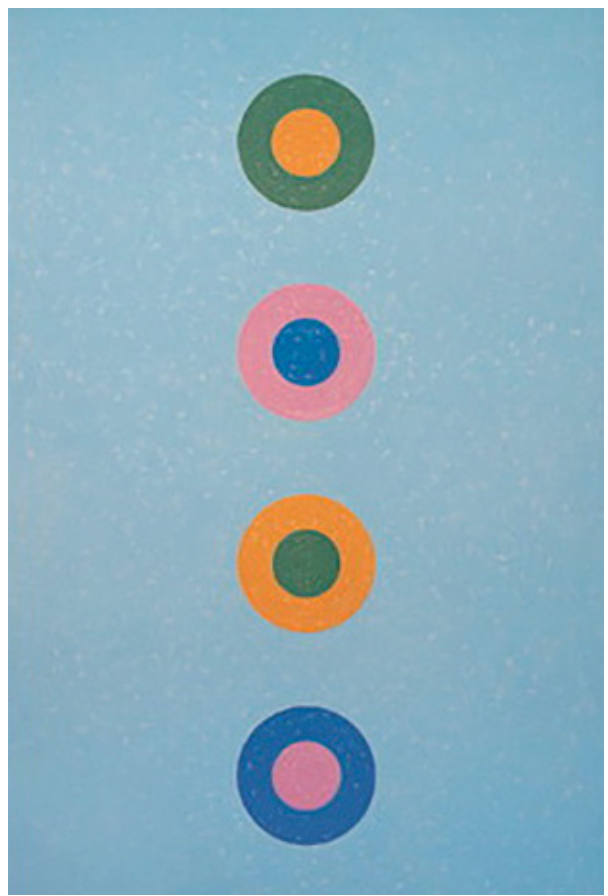

\section{INTRODUÇÃO}

Mats Alvesson e Dan Kärreman publicaram no Journal of Applied Behavioral Science, em junho de 2000, um influente artigo sobre a análise do discurso organizacional, onde afirmam posição contrária ao entendimento comum, à época, que concebia a linguagem como um espelho fiel da realidade (paradigma da linguagem como representação) ${ }^{1}$ e, como consequência, tomava os instrumentos metodológicos de pesquisa - que, em última instância, são recursos discursivos de base argumentativa quantitativa ou qualitativa - como um meio seguro para a produção do conhecimento em ciência. Essa perspectiva começou a ser criticada pela filosofia e pelos próprios linguistas - por meio do trabalho dos analistas do discurso - que passaram a compreender a linguagem como um elemento constitutivo da realidade (cf. ALVESSON e KÄRREMAN, 2000a; RECKWITZ, 2002; SCHATZKI, 2000; WODAK, 2004). Em Foucault (1992), por exemplo, a epistéme de uma época é vista como um dispositivo discursivo que possibilita a seleção de enunciados possíveis no interior de um campo científico, isto é, que possibilita o julgamento do que é qualificável ou não na ciência, tornando-se um meio de ordenação do saber-poder.

Como um contraponto à visão tradicional da linguagem, Alvesson e Kärreman (2000a) apresentam novos princípios ontológicos, reunidos sob o rótulo de virada linguística (linguistic turn)². Sob esse viés, a linguagem é vista como: (1) um modo de expressão; (2) o objeto central de estudo nas ciências sociais; (3) um recurso para estabelecimento de credibilidade; (4) a matéria-prima de trabalhos dos pesquisadores; (5) portadora/condutora de relações de poder por meio de sua propriedade de ordenar o mundo social; (6) um meio de manifestação de posicionamentos críticos; (7) metafórica e capaz de construir significados e fenômenos; (8) uma resultante da linguagem em uso em um contexto socialmente situado, isto é, em um contexto demarcado por um espaço-tempo e pela cultura e normas sociais.

\footnotetext{
*Fonte da imagem: Ivan Serpa (1972). Série Geomântica. Disponível em: <https://www.wikiart.org/en/ivan-serpa/s-rie-geom-ntica-1972-1>. Acesso em 15 jun. 2016.

${ }^{1}$ Tal paradigma apoia-se na ideia de que as palavras possuem significados fixos, isto é, representam e estão (previamente) ligadas a objetos, sejam eles instâncias da vida íntima dos indivíduos (intenções, cognição, valores e sentimentos) ou de sua esfera social (práticas e interações sociais) (ALVESSON e KÄRREMAN, 2000a).

${ }^{2}$ Essa expressão é originária da década de 1930, tendo sido empregada pelos fenomenologistas que defendiam uma posição epistemológica que superasse o dualismo sujeito/objeto e a compreensão, exclusivamente, psicológica da experiência humana, possibilitando, nesse novo quadro, que a linguagem fosse vista além de um mero espelho da realidade, como a lente positivista a concebia (DEETZ, 2003).
} 
Nessa perspectiva, a linguagem, como objeto de estudo a ser incorporado nas ciências sociais, deve ser pensada em três dimensões: a linguagem propriamente dita (seu aspecto textual); a linguagem em uso; e as condições de produção do discurso (ALVESSON e KÄRREMAN, 2000a). A primeira delas ressalta que a linguagem deve ser vista como um sistema de diferença em oposição à noção de que o discurso carrega significados universais e rígidos. Essa ideia pode ser explicada pelo conceito de différance de Jacques Derrida (cf. TOLEDO e SILVA, 2014)³ ${ }^{3}$ que, em resumo, sugere que o significado de qualquer palavra ou frase é derivado do processo de diferimento em relação a outras palavras ou frases. O filósofo critica formas de pensar que creem na conceituação de um elemento em si mesmo, como se o próprio elemento possuísse um fundamento, uma substância, um princípio que remeta apenas a si mesmo (DERRIDA, 2001a; 2001b). Como alternativa, propõe que o processo de significação ocorre por meio de uma rede de significações (também chamada de texto, escritura ou, simplesmente, rede).

Seja na ordem do discurso falado, seja na ordem do discurso escrito, nenhum elemento pode funcionar como signo [significante/significado] sem remeter a um outro elemento, o qual ele próprio, não está simplesmente presente. Esse encadeamento faz com que cada "elemento" - fonema ou grafema - constitua-se a partir do rastro, que existe nele, dos outros elementos da cadeia ou sistema. Esse encadeamento, esse tecido, é o texto que não se produz a não ser na transformação de um outro texto. Não existe, em toda parte, a não ser diferenças e rastros de rastros (DERRIDA, 2001b, p. 32).

Portanto, a linguagem é um sistema de diferenças, formado pelos rastros de significados. Tal imprecisão sugere, exatamente, que os significados não são fixos/rígidos (não há uma união "natural", independente do social, entre significante - forma -e significado ${ }^{4}$ ), eles podem mover-se livremente. É a realidade de determinado grupo social, como portadora de uma metalinguagem (COOPER, 1990), que confere sentido/significado aos textos produzidos pelos falantes.

A segunda dimensão refere-se à linguagem em uso, ou seja, ao discurso produzido nas interações cotidianas. As palavras "colocadas em ação" são compreendidas como práticas sociais. Só faz sentido estudar a linguagem em seu uso, não como um objeto descolado do falante e do contexto. As ideias de Ludwig Wittgenstein foram precursoras nessa direção. A realidade social é compreendida pelo filósofo como um nexo de práticas e a ação é o momento em que os fenômenos sociais, como as instituições, por exemplo, são mais bem compreendidos por meio de relações entre tais práticas. Nessa perspectiva, a compreensão da linguagem enquanto prática social se dá no momento do uso (SCHATZKI, 2000).

A terceira dimensão do framework enfatiza que conceitos como liderança, hierarquia, estratégia, decisão, entre outros, não podem ser entendidos fora do seu contexto de uso, mas também de produção (ALVESSON e KÄRREMAN, 2000a). Assim, um discurso é algo que se materializa a partir das condições sociais que possibilitam sua produção. Um discurso nasce a partir de certas condições políticas e ideológicas e também reproduz tais condições, podendo ser modificado ao longo de seu uso (consumo/interpretação).

Em setembro do mesmo ano (2000), um novo paper foi publicado pelos autores, na Human Relations, propondo um framework para o mapeamento das análises de discurso utilizadas nos estudos organizacionais (EO). Uma das dimensões desse modelo chama a atenção para as análises que focam o aspecto situacional (a análise da linguagem em uso circunscrita ao microcontexto) (ALVESSON e KÄRREMAN, 2000b). Os autores denominaram tais abordagens discurso, com "d" minúsculo, ou, em Alvesson e Kärreman (2011), text-focused studies (TFS). No outro extremo, estão as análises de discurso, como a foucaultiana, centradas em narrativas de alcance abrangente, ligadas à epistéme e à ideologia de uma época. Tal perspectiva foi identificada como Discurso, com "D" maiúsculo, ou, em Alvesson e Kärreman (2011), paradigm-type discourse studies (PDS). Há uma clara mudança de entendimento sobre as possibilidades de conectar as duas dimensões do framework. Em Alvesson e Kärreman (2000a, 2000b), a opinião manifestada é que tais dimensões podem ser aproximadas - e, em certo sentido, esse deveria ser o cenário ideal -, apesar de reconhecerem o desafio desse empreendimento e demonstrarem certa impossibilidade de alcançá-lo.

Algumas vezes, pesquisadores desejam incorporar em suas análises os níveis micro e macro. Fairclough (1993: 138), por exemplo, está interessado no discurso, no sentido da linguagem falada ou escrita

\footnotetext{
${ }^{3}$ A noção de différance é formulada, por Derrida, a partir do conceito, do linguista e filósofo suíço Ferdinand de Saussure, da linguagem como sistema de diferenças (COOPER, 1990).

${ }^{4}$ Saussure denominou essa noção princípio da arbitrariedade entre significante/significado (CUNHA, 2008).
} 
utilizada no nível da prática discursiva, na medida em que ela se refere a "uma ordem do discurso", "a totalidade da prática discursiva de uma instituição e das relações entre elas". Nós achamos que há uma tensão entre os dois níveis. Investigações baseadas na construção local do discurso consideram o discurso como um fenômeno emergente e localmente construído, ao passo que os estudos sobre Discursos usualmente partem de compreensões estabelecidas a priori sobre o fenômeno em questão. Não é fácil, nós acreditamos, combinar ambos os pontos de vista, cuidadosamente, no mesmo estudo. Isso não deveria, entretanto, desencorajar tal esforço. $O$ rigor deveria, às vezes, ser subestimado em benefício da relevância social (ALVESSON e KÄRREMAN, 2000b, p. 1134, grifo dos autores, tradução nossa).

Em sua conclusão, Alvesson e Kärreman (2000b) retomam a questão e apresentam-na como um desafio para os analistas do discurso organizacional, embora, como indicado, haja uma atmosfera de incredulidade quanto à existência de um caminho analítico que viabilize tal iniciativa. Em Alvesson e Kärreman (2011), o discurso ultrapassa o tom de desafio e assume que é necessária uma ruptura entre as dimensões micro e macrodiscursivas. A partir do exame de diversas propostas de análise de discurso, os autores concluem que não é possível, metodologicamente (do ponto de vista empírico, não por definição ${ }^{5}$ ), realizar tal aproximação de modo satisfatório.

A fim de suportar a primeira estratégia [desconectar discurso e Discurso] sugerimos dois novos conceitos, como uma forma de ir além do problema dos discursos inflamados sobre o discurso: estudos focados no texto [text-focused studies] (TFS) e estudos do tipo paradigma [paradigm-type discourse studies] (PDS) são talvez palavras/significados que melhor indicam o que as pessoas estão fazendo, quando falam em discurso com a letra d minúscula e com a letra D maiúscula. A sugestão de distinguir entre letras minúsculas e maiúsculas em Alvesson e Kärreman (2000b) não foi talvez muito útil, pois deu a impressão de que era um modo fácil de separar e integrar os fenômenos ou aspectos que, talvez, realmente necessitem de abordagens diferentes e de um trabalho duro para conectá-los (ALVESSON e KÄRREMAN, 2011, p. 1142, tradução nossa).

No entanto, cumpre registrar que não há nas publicações de Alvesson e Kärreman (2000a; 2000b; 2011) uma análise do trabalho de Norman Fairclough - como não há menção à análise crítica do discurso (ACD), de forma geral -, apesar de haver, em Alvesson e Kärreman (2000b; 2011), breves menções a esse autor ${ }^{6}$.

Diante dessa constatação, entendemos, contrariamente ao posicionamento de Alvesson e Kärreman, especialmente aquele apresentado no paper "Decolonializing discourse: critical reflections on organizational discourse analysis", de 2011, que é necessário buscar uma aproximação dialética entre os discursos localmente situados e as ordens discursivas estabelecidas; e que o mérito da ACD de Norman Fairclough e colaboradores é escapar do relativismo (ou reducionismo) linguístico, exatamente por levar em consideração a articulação entre os níveis mencionados, não menosprezando a capacidade de agência dos indivíduos e não assumindo o determinismo das estruturas. A proposta de Fairclough pode ser assimilada como uma linha de fuga para a armadilha presente nas abordagens discursivas que estacionam nos extremos reducionistas de investigação por meio da linguagem (micro ou macro) ${ }^{7}$. Alvesson e Kärreman (2000a; 2000b; 2011), ao que parece, não examinaram com cautela as soluções de Fairclough ${ }^{8}$ para as problematizações por eles levantadas ${ }^{9}$.

Partindo de tal contexto, este artigo tem por objetivo suprir essa lacuna, apresentando a abordagem de Norman Fairclough como uma alternativa de ampliação das opções teórico-metodológicas para as pesquisas em administração. A abordagem discursiva proposta pelo autor inglês persegue os significados para além do texto, escavando as condições em que foi produzido,

\footnotetext{
${ }^{5}$ Ver Alvesson e Kärreman (2011, p. 1130).

${ }^{6}$ Cumpre registrar que, em Alvesson e Kärreman (2000a), não há menção a Norman Fairclough ou outro autor vinculado ao corpo teórico da ACD.

7 Magalhães (2001, p. 24) reforça nossa interpretação sobre o posicionamento epistemológico da ACD, ao salientar que o trabalho de Fairclough tenta combinar três tradições analíticas no campo da linguística aplicada: "a tradição de análise linguística e textual da linguística, a tradição macrossociológica de análise da prática social em relação às estruturas sociais e a tradição interpretativa ou microsociológica de análise da prática social enquanto ativamente produzida e entendida pelas pessoas com base em procedimentos compartilhados de senso comum". Cabe complementar que apesar de reconhecerem a contribuição de Alvesson e Kärreman para o campo do discurso nos EO, Phillips e Oswick (2012) e Grant e ledema (2005) mencionam a limitação do framework elaborado pela dupla para mapear as possibilidades de uso de referenciais teóricos-metodológicos ligados à análise do discurso nas organizações. ${ }^{8} \mathrm{O}$ que não quer dizer, naturalmente, que a ACD seja um percurso teórico isento de falhas. Sobre as críticas a seu respeito, ver Rodrigues-Júnior (2009).

${ }^{9}$ Essa afirmativa não minimiza a contribuição dos autores para o campo dos EO. Alvesson e Kärreman são pesquisadores com longa e respeitada atuação e, portanto, importantes formadores de opinião. Por tal razão, entendemos que é relevante denotar essa ausência, com o intuito de difundir para a comunidade acadêmica brasileira outras possibilidades de análise de discurso, além daquelas mencionadas pelos autores.
} 
veiculado e consumido e observando a materialidade gerada por tais discursos (constituição de instituições, de relações de poder, de identidade, de crenças etc.), portanto, seu foco está na relação dialética entre linguagem e realidade social, a partir de uma perspectiva que busca evidenciar as ideologias e as relações de poder reificadas no discurso (FAIRCLOUGH, 1985), daí decorre sua natureza crítica ${ }^{10}$. Chouliaraki e Fairclough (1999) reforçam que um dos compromissos centrais da ACD é revelar as ideologias subjacentes aos discursos, denunciando seu papel como elemento de dominação. Acreditam os autores que somente desvelando as formas de dominação imbricadas no discurso é que os sujeitos sociais são capazes de desenvolver práticas emancipatórias, utilizando o conhecimento sobre a vida como um meio de transformação social. Por tal inclinação, advogamos que a $A_{C D}{ }^{11}$ não deve ser vista como um recurso metodológico. Chouliaraki e Fairclough (2010, p. 1215, tradução nossa) são enfáticos ao condenar a redução da ACD a uma técnica universalista de pesquisa, dado que a "ACD é um modo de investigação crítica, onde teoria e metodologia estão intrinsecamente inter-relacionadas". Essa via de pensamento abre espaço para enxergar a realidade organizacional sob novos ângulos, acoplando o subsídio teórico utilizado nas pesquisas organizacionais (sobre temas variados, tais como liderança, gênero, trabalho, estratégia, consumo, entre outros) à perspectiva crítica de Fairclough ${ }^{12}$.

Após introduzir a problemática da linguagem nos estudos organizacionais e anunciar a proposta de Fairclough como um caminho promissor para conectar linguagem, mundo e ideologia, o próximo tópico traz um breve histórico sobre a análise de discurso e descreve os princípios centrais da teoria do discurso de Norman Fairclough. Na sequência, discorremos sobre a concepção tridimensional do discurso presente na ACD, para, em seguida, abordar os usos da ACD nos EO brasileiros. Encerramos ponderando sobre as implicações da ACD para as investigações acadêmicas no campo em tela.

\section{A TEORIA SOCIAL DO DISCURSO DE NORMAN FAIRCLOUGH}

Os primeiros estudos sobre a análise de discurso (AD) entendiam o discurso como uma extensão linguística, não incorporando em sua base teórica a concepção da linguagem como constituinte da realidade e dos sujeitos. A vertente europeia da $A D$ (representada, principalmente, pela corrente francesa e inglesa) ${ }^{13}$ modificou esse paradigma, por acreditar haver uma relação entre o que se diz e as condições de produção dessa fala, atentando para um sentido no exterior do texto e, portanto, atribuindo importância à posição sócio-histórica dos enunciadores (BRANDÃO, 2002).

A origem institucional da $A C D$ - um ramo da linguística aplicada - remonta a um breve simpósio, de apenas dois dias, realizado, em janeiro de 1991, na cidade de Amsterdã (Holanda) ${ }^{14}$. Por meio do apoio da Universidade de Amsterdã, os pesquisadores Teun van Dijk, Norman Fairclough, Gunther Kress, Teo van Leeuwen e Ruth Wodak debateram teorias e métodos de análise de discurso, esboçando, mas não delimitando, um escopo para a ACD. O encontro foi o momento em que experiências de pesquisa, diferenças e semelhanças teóricas e metodológicas foram expostas, a fim de traçar programas com o intuito de tornar a ACD uma vertente reconhecida da linguística aplicada, sem que a heterogeneidade do grupo fosse dispersada. A partir desse episódio, uma rede de pesquisa foi criada por meio de periódicos, como a revista Discourse and Society, já em 1990, e editada por Van Dijk, e vários livros ao longo da década (WODAK, 2004) ${ }^{15}$.

\footnotetext{
${ }^{10}$ Um paralelo, no campo dos EO, à noção de crítica de Fairclough pode ser encontrado em Davel e Alcadipani (2003), para quem uma teoria administrativa que se autointitula "crítica" deve ocupar-se de (1) difundir uma visão desnaturalizada da administração, enfatizando seu caráter histórico e conflituoso; (2) ter intenções desvinculadas da noção de performance (lógica regida pela ideia de maximização de outputs com um mínimo de inputs); (3) ter uma intenção emancipatória, na medida em que combata ideias que geram opressão ao ser humano, buscando incentivar o empoderamento e a responsabilidade individual/coletiva.

${ }^{11}$ Alguns autores, como Magalhães (2005), preferem traduzir a expressão critical discourse analysis, grafia original na língua inglesa, como análise de discurso crítica (ADC)

${ }^{12}$ Essa orientação analítica para a construção de pesquisas utilizando a ACD está perfeitamente clara nos textos: Chouliaraki e Fairclough (1999; 2010) e Fairclough (2005b).

${ }^{13} \mathrm{~A} A D$ inglesa (como a $A C D$ é, por vezes, chamada), quando comparada com a $A D$ francesa, apresenta, na opinião de alguns autores, uma visão acentuadamente dialética entre as instituições sociais e as ações individuais, conferindo maior relevância à possibilidade de transformação social e menor ênfase ao determinismo das estruturas sociais (RODRIGUES e DELLAGNELO, 2012). No entanto, não é objeto deste artigo explorar as possíveis diferenças entre as vertentes francesa e inglesa nem questionar o quanto seria razoável chamar a ACD de AD inglesa.

${ }^{14}$ Sobre informações históricas da ACD e suas influências teóricas absorvidas das ciências sociais e do pragmatismo linguístico, ver Fowler (2004) e Wodak (2004).

${ }^{15}$ Para um breve panorama sobre periódicos e coletâneas de livros ligados à ACD lançados, no exterior, até a primeira metade da década passada, ver Magalhães (2005). No Brasil, no campo dos estudos linguísticos há o número especial, publicado em 2005, pela D.E.L.T.A., revista de linguística e linguística
} 
Norman Fairclough é um dos expoentes desse movimento, dedicando-se a estabelecer as principais teorias sociais e metodologias que sustentam a ACD, publicando livros e artigos, e

[...] mostrando não somente como o quadro analítico para investigar a linguagem em relação ao poder e à ideologia se desenvolveu, mas também como a ACD é útil para revelar a natureza discursiva de muitas das mudanças sociais e culturais contemporâneas (WODAK, 2004, p. 230-231).

Sua teoria social do discurso tem o propósito de

[...] reunir a análise de discurso orientada linguisticamente e o pensamento social e político relevante para o discurso e a linguagem, na forma de um quadro teórico que será adequado para uso na pesquisa científica social e, especificamente, no estudo da mudança social (FAIRCLOUGH, 2001a, p. 89).

O emprego do termo discurso possui, para o linguista, duas acepções distintas, segundo Fairclough (2000; 2001a; 2001b): (1) discurso como substantivo abstrato, significando uma denominação genérica para o texto escrito, falado ou qualquer tipo de semiosi, tais como gestos e imagens. Em Chouliaraki e Fairclough (1999), discurso é conceituado como elemento semiótico - ou uma combinação deles - da prática social; (2) discurso como um substantivo concreto, significando um modo de construção de sentido das experiências vividas, a partir de uma perspectiva particular, como, por exemplo, um discurso feminista sobre a sexualidade. Esta última acepção é grafada, em algumas de suas obras, como discursos, no plural. Nessa perspectiva, discurso é sinônimo de prática discursiva, um elemento das práticas sociais, noção desenvolvida adiante. Dito de outro modo, ele é o ponto de articulação entre elementos linguísticos e extralinguísticos ou "a linguagem como manifestação da ideologia, prática social que medeia o homem e sua realidade" (SOUZA e CARRIERI, 2014, p. 16).

Portanto, ao usar o termo discurso, o autor propõe que o uso da linguagem seja visto como uma forma de prática social e não uma atividade individual, um reflexo exclusivo de variáveis situacionais, um resultado do background knowledge ${ }^{16}$ ou, ainda, uma forma instrumental que se presta, somente, à comunicação entre os homens. Para Fairclough (1995; 2001a; 2005a), as implicações desse pensamento são:

- $\quad$ existe uma relação dialética entre o discurso (como prática) e as práticas sociais17 estabelecidas na sociedade, de tal forma que o discurso é condicionado pelas práticas sociais não discursivas, ao mesmo tempo que as condiciona;

- os aspectos constitutivos do discurso e das práticas sociais são exercidos por meio dos textos;

- o discurso cumpre a função de dotar a experiência humana de sentido;

- a formação dos signos (palavras ou sequências longas do texto dotadas de um significado combinado com uma forma) é um processo social, na medida em que as convenções sociais são responsáveis por associar um significante (forma) particular a um significado (conteúdo) particular;

- O significado de uma forma linguística é variável, assumindo entendimentos diversos, sobrepostos, complementares ou mesmo contraditórios. Os textos estão sempre abertos a múltiplas interpretações. Os leitores escolhem um sentido possível ou um subconjunto deles. Assim, o sentido de um signo é sempre dependente da interpretação e também não há uma forma linguística separada de sentido.

Enfocaremos os três primeiros pontos enumerados, dado que os últimos são princípios estruturantes da ACD e permeiam os conceitos apresentados adiante.

aplicada publicada pela Pontifícia Universidade Católica de São Paulo (PUC-SP) e o livro Reflexões sobre a análise crítica do discurso, organizado por Célia Magalhães e publicado em 2001, obra que traz trabalhos de pesquisadores do programa de pós-graduação em estudos linguísticos da Universidade Federal de Minas Gerais (UFMG).

${ }^{16}$ Certos autores entendem o discurso como o resultado de um background knowledge (BGK), o que seria para Fairclough uma redução não aceitável, pois significaria a concordância com o fato de que conhecimento, tomado como uma verdade universal, e ideologia, entendida como uma versão possível da realidade que se constrói a partir de determinado ponto de vista, são sinônimos (FAIRCLOUGH, 1985; 1995).

${ }^{17}$ Em alguns de seus textos - como em Fairclough (2001a) -, o linguista inglês afirma a existência de uma relação dialética entre discurso e estrutura social. Em outras circunstâncias, a expressão práticas sociais é mais frequente - arriscamos dizer que, nos textos escritos a partir de Chouliaraki e Fairclough (1999), esta última expressão é mais comum. Práticas sociais, para Fairclough (2005a), são um elemento de mediação entre a estrutura social e os eventos sociais (o mesmo que atividades/fenômenos/fatos sociais). Uma prática social representa, portanto, aquilo que, de fato, ocorre na vida diária, diante das condições de possibilidade engendradas pelas estruturas sociais e conforme a ação dos sujeitos sociais. 


\section{A dialética prática discursiva e prática social}

Em Chouliaraki e Fairclough (1999), a prática discursiva é conceituada como um momento semiótico, um momento da prática social, entre outros momentos existentes ${ }^{18}$. Os estágios de produção/veiculação/interpretação do texto articulam-se com outros momentos das práticas sociais (momentos/elementos não semióticos). Essa articulação é realizada pelos sujeitos sociais (reflexividade presente na prática discursiva), que, a seu modo, internalizam as práticas sociais e constroem uma prática discursiva própria (FAIRCLOUGH, 2005b). Enxergar o discurso sob essa perspectiva implica que um fato organizacional, como a competitividade entre empresas, pode ser visto como um evento discursivo, na medida em que a competitividade torna-se uma realidade concreta por meio de distintas ações discursivas, tais como campanhas publicitárias e materiais promocionais; divulgação de preços, atributos e benefícios dos itens nos locais de venda; embalagens em que os produtos são acondicionados; estratégias persuasivas de venda, utilizadas pelos vendedores/representantes comerciais; discursos institucionais sobre a missão da empresa, seus valores, ações etc. Esse conjunto discursivo (que, na verdade, trata-se de ideias que disputam e rogam a atenção dos consumidores) estabelece uma atmosfera de competição entre as empresas, influenciando, por sua vez, a criação de uma práxis de mercado, caracterizada, entre vários aspectos, pela necessidade das empresas em criar redes de logística para assegurem suas promessas de venda, em organizar escritórios administrativos etc. Portanto, os discursos têm efeitos não discursivos (FAIRCLOUGH, 2005b) ${ }^{19}$, isto é, modificam a forma de agir das pessoas, seu modo de pensar, a forma como se relacionar com os objetos ao redor, entre outros. Um desdobramento relevante desse ponto de vista é que a adoção da ACD não obriga o pesquisador a considerar os fatos sociais, unicamente, como discursos. Retornando ao exemplo dado, vemos que a competitividade empresarial é co-constituída por discurso e fatores não discursivos. Os valores e as crenças dos consumidores influenciam, sobremaneira, a decisão de compra e esse é um elemento não discursivo.

Dessa forma, podemos refletir, seguindo Fairclough, sobre esta questão: fenômenos, como a competitividade empresarial, liderança, diversidade organizacional, e assim por diante, não são autoevidentes. Pelo contrário, são resultado de um processo de construção social denotado pela dialética entre discurso e materialidade, cujo pano de fundo são as disputas pelo estabelecimento de posições ideológicas hegemônicas. Tal articulação dialética é, portanto, reflexiva - dependente do indivíduo, denotando o papel ativo do sujeito na relação sujeito/linguagem/mundo - e dependente do contexto social, denotando a influência conjuntural, portanto, histórica. Depreende-se dessa linha de raciocínio que o discurso é sempre uma simplificação (condensação ou subjetivação) de realidades complexas (FAIRCLOUGH, 2005b), operada por meio da seleção lexical, da articulação com outros textos e convenções discursivas pré-estabelecidas, do conteúdo não dito etc. ${ }^{20} \mathrm{~A}$ simplificação discursiva seria infinita não fossem as relações de poder que caracterizam o jogo social.

Esse processo, como um todo, é denominado por Fairclough (2005b) dialética do discurso ${ }^{21}$.

\section{Os aspectos constitutivos do discurso e das práticas sociais refletidos no texto}

A realidade social, materializada pelas práticas sociais, manifesta-se (discursivamente) por meio das práticas discursivas, isto é, ela influencia a produção/criação, a veiculação e o consumo/interpretação dos discursos, deixa "marcas" no texto (por isso, as práticas discursivas podem ser estudadas por meio da análise textual/linguística) e configuram ordens discursivas. Assim, "o emprego do discurso é sempre orientado socialmente, ou seja, a linguagem se faz para um uso prático, seja este qual for, de dominação, de conscientização, educativo, reflexivo, de crítica, dentre outros" (CORTEZ, 2003, p. 25). Dessa forma, o discurso

\footnotetext{
${ }^{18} \mathrm{~A}$ prática discursiva é um elemento/tipo (ou um momento) de prática social. Ela pode ser compreendida como a face discursiva da prática social, ao lado dos elementos físicos, sociológicos e culturais/psicológicos (CHOULIARAKI e FAIRCLOUGH, 1999; FAIRCLOUGH, 2000) em sintonia com os pressupostos da teoria da prática (SCHATZKI, 2005) - ver Resende e Ramalho (2004) para uma explicação esclarecedora a respeito dessa concepção em Chouliaraki e Fairclough (1999). Sugerimos o texto de Santos e Silveira (2015) para complementar o entendimento do conceito de prática social e exemplificar como ele pode ser incorporado ao campo dos EO.

${ }^{19}$ Característica denominada materialidade discursiva.

${ }^{20}$ Diversos fatores interferem nesse processo de simplificação: (1) seletividade estrutural; (2) escopo e alcance do discurso na sociedade; (3) capacidade dos agentes sociais de difundir o discurso, mediante os circuitos midiáticos; (4) a ressonância do discurso, junto aos sujeitos ordinários e às instituições (FAIRCLOUGH, 2005b).

${ }^{21}$ Esse pensamento dialético evita erros típicos de posições extremistas de analistas do discurso, que chegam a considerar que a constituição discursiva emana de um livre jogo de ideias na cabeça das pessoas ou, em outro extremo, que é decorrente das estruturas discursivas (códigos, convenções e normas) e não discursivas (FAIRCLOUGH, 1995; 2001a).
} 
é constituído pelas identidades sociais (individuais e coletivas); relações sociais e sistemas de conhecimento e crenças, conforme Fairclough (2001a). Se a realidade social informa o discurso ele é, então, um tipo de prática social. As problemáticas sociais estão refletidas no texto e são investigadas, naturalmente, a partir do próprio texto, matéria-prima do analista. É por esse caminho que linguagem e mundo estão imbricados e é por essa via que a linguística se liga às ciências sociais e, mais especificamente, ao campo dos estudos organizacionais.

A ação no sentido contrário também ocorre, isto é, o discurso, por meio das ordens do discursos estabelecidas de modo mais ou menos estável, também cria o mundo, gera ações concretas, sentimentos, formas de agir, de relacionar-se, de pensar, gera um sentido moral, cria instituições etc. Por essa razão é que Fairclough defende a possibilidade de transformação do mundo (mudanças nas formas hegemônicas prevalecentes na sociedade) por meio do discurso e das relações que este estabelece com as demais facetas da vida social. Fairclough deixa clara a interdependência entre linguagem e mundo. A linguagem é constituída pelo mundo/social/cultural (função de representação ou de reprodução), ao mesmo tempo que constitui o mundo/social/cultural (função de produção/criação, função de mudança/agência).

\section{As funções do discurso}

Como indicado, Fairclough (2001a, p. 91) ensina que "o discurso é uma prática, não apenas de representação do mundo, mas de significação do mundo, constituindo e construindo o mundo em significado". Três tipos de sentidos possíveis (ou de significado) são destacados pelo linguista: (1) um modo de agir, isto é, um sentido acional ou relacional; (2) um modo de representar, isto é, um sentido representacional; (3) um modo de ser e de posicionar-se na sociedade, isto é, um sentido identitário. Um discurso, portanto, estabelece sentidos para a realidade ao redor. Resumidamente, cada um desses sentidos sociais que o texto possibilita corresponde, respectivamente, às seguintes funções da linguagem ${ }^{22}$ : relacional (modo como as relações sociais entre os participantes do discurso são representadas e negociadas); ideacional (modos pelos quais os textos significam/representam o mundo, seus processos, entidades e relações, contribuindo para a construção de conhecimentos e crenças sobre a realidade em que se vive); e identitária (modos como as identidades sociais, individuais e/ou coletivas são estabelecidas no discurso). Essas três funcionalidades da linguagem são apresentadas de modo separado por uma questão didática. Empiricamente, elas se manifestam simultaneamente na linguagem em uso. Além dessas, há uma função textual referente à análise linguística (estrutura e organização, seleção lexical, coerência etc.) do texto (FAIRCLOUGH, 2001a).

A linguagem enquanto manifestação social desempenha suas funções por meio de uma permanente negociação entre sujeito e as ordens de discurso estabelecidas. Do ponto de vista linguístico, as ordens de discurso são convenções discursivas criadas a partir da hibridização de gêneros, de intertextualidades, interdiscursividades e dos estilos, conceitos explicitados no tópico seguinte. Sob a perspectiva da teoria social, são manifestações ideológicas que representam interesses de agentes sociais (os enunciadores do discurso: indivíduos, empresas, instituições governamentais etc.) em disputa pela prevalência (luta hegemônica) em determinado campo de atividade. A ACD une essas duas visões sobre a ordem do discurso. Os sujeitos sociais receptores desse discurso apreendem reflexivamente esse saber ideológico reificado, de tal forma que o processo de representação do mundo em que vivem (assimilação de saberes, de valores etc.) sempre possui uma carga de subjetividade, isto é, o sujeito age e não é mero sujeito "assujeitado" (ele se constitui na ambivalência desses dois estados). Assim, por intermédio dessa dinâmica, o discurso termina por constituir identidades, modelar relações sociais e as formas de conceber/ler o mundo, como mencionado.

Na sequência, as concepções ontológicas e epistemológicas que fundamentam a ACD são desdobradas nos termos do modelo tridimensional do discurso de Norman Fairclough (2001a), proposto em 1992 e complementado e revisto por estudos posteriores ${ }^{23}$.

\footnotetext{
${ }^{22}$ O linguista inglês Michael Alexander Kirkwood Halliday dedicou-se, desde a década de 1970, ao desenvolvimento de um framework de análise linguística a partir do enquadramento teórico geral conhecido como systemic functional linguistics (SFL), tendo proposto que a linguagem desempenha três metafunções: ideacional, interpessoal e textual (MARTIN, 1997). Fairclough (2001a) desmembrou a macrofunção interpessoal em identitária e relacional.

${ }^{23}$ Reconhecemos que o estudo de Chouliaraki e Fairclough (1999) trouxe mudanças à ACD, acentuando sua articulação com a ciência social crítica, como bem denotaram Resende e Ramalho (2004). Respeitamos e reconhecemos as pontuações das autoras nessa direção. Nossa opinião, no entanto, é que as pesquisadoras não relacionaram de modo fluido o quadro tridimensional, de Fairclough (2001a), proposto em 1992, com as formulações de Chouliaraki e Fairclough (1999), fazendo parecer que o primeiro estaria, ao menos parcialmente, superado ou desatualizado ou, ainda, que Norman Fairclough não mais o utiliza. Chouliaraki e Fairclough (1999) mostram que, na sociedade contemporânea (sociedade da modernidade tardia), o discurso exerce uma força crescente
} 


\section{A CONCEPÇÃO TRIDIMENSIONAL DO DISCURSO}

Examinamos, a seguir, como os pressupostos gerais da teoria social do discurso de Norman Fairclough dão vida à $A C D$, sob a forma de uma concepção tridimensional do discurso, representada na Figura 1.

Figura 1

\section{Concepção tridimensional do discurso}

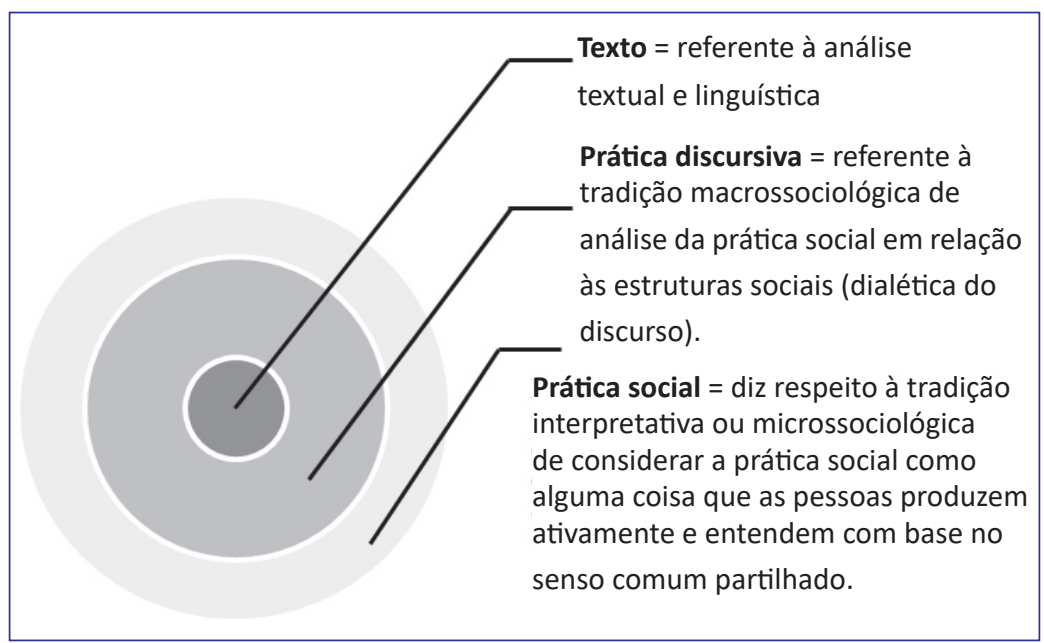

Fonte: Adaptada de Fairclough (2001a).

Abordamos na sequência cada uma das dimensões, buscando tornar clara a ligação entre realidade social, discurso (como semiosi e um tipo de prática social), ideologia e hegemonia.

\section{Análise textual}

Como indicado, no item anterior, o texto apresenta uma diversidade funcional, podendo ser tomado, no escopo da ACD, como um meio de representação e significação do mundo e das experiências vividas e como um meio de constituição de identidades e de relações sociais entre os sujeitos. A análise do texto busca revelar essas funções da linguagem por meio do exame da seleção lexical (vocabulário), da gramática, das relações de coesão/coerência, da estrutura e organização geral, dos silêncios no texto, entre outros aspectos (FAIRCLOUGH, 2001a; 2001b). Na perspectiva da ACD, entende-se que tais características textuais obedecem princípios exteriores ao texto, isto é, elas estão ligadas a práticas sociais e constituem, por conseguinte, dados sociais. Dessa forma, as propriedades formais de um texto não são fruto de uma escolha aleatória por parte dos enunciadores, elas estão vinculadas a uma posição social, a um modo de viver e de pensar o mundo.

na constituição das práticas sociais, isto é, as lutas hegemônicas são travadas, principalmente, por meio de lutas discursivas. Esse é um traço característico da sociedade atual, que demanda/justifica a relevância de abordagens discursivas, como a ACD, para as pesquisas em ciências sociais. No livro, a dupla amplia o diálogo com as teorias sociais (referências são feitas a Habermas, Giddens, Harvey, Foucault, Baudrillard etc.), buscando refletir, exatamente, sobre os efeitos "genéricos" da contemporaneidade (i. e., das práticas sociais do nosso tempo) nas práticas discursivas, e vice-versa. Diante desse entendimento, interpretamos as contribuições de Chouliaraki e Fairclough (1999) como uma atualização da tridimensionalidade originalmente proposta por Fairclough, na medida em que o trabalho de 1999 reforça o preceito central da ACD: a circularidade bidirecional entre as dimensões textual, da prática discursiva e da prática social. Tal cotejamento é feito, com propriedade, por Cortez (2003), em sua pesquisa de mestrado. 


\section{Análise da prática discursiva}

A prática discursiva é a dimensão da $A C D$ que trata da produção, veiculação e interpretação textual como ações vinculadas ao contexto social (FAIRCLOUGH, 2001a). Enquanto forma linguística, a prática discursiva realiza-se no texto ${ }^{24}$ (ou em outras formas semióticas em análise) (MAGALHÃES, 2001). Ou seja, um analista do discurso tem em sua matéria-prima, o texto, duas fontes de informação: a análise textual (exame das propriedades formais), indicada anteriormente; e a análise da prática discursiva, realizada por meio da observação das convenções discursivas refletidas no texto, isto é, das ordens do discurso. Um texto, por conseguinte, revela informações que vão além de seus aspectos linguísticos formais, quando, por exemplo, faz uso de gêneros linguísticos, faz referência a outros textos, a outros discursos etc. Essa dimensão informacional é capturada pela análise das práticas discursivas. Esse processo ocorre por meio das categorias analíticas - gênero, intertextualidade, interdiscursividade e estilo - que constituem uma ordem de discurso. Tais conceitos são explicados na sequência.

A sociedade pode ser compreendida como um complexo de práticas sociais, constituído por elementos discursivos e não discursivos (FAIRCLOUGH, 2005a). A ordem do discurso é a faceta discursiva dessas práticas sociais, vinculadas a determinado grupo social, sendo, normalmente, formada por diversas outras ordens de discurso. De modo mais sofisticado, Fairclough (2005a, p. 925) elabora o conceito como

[...] estruturações sociais de variação ou diferença linguística/semiótica. Isso quer dizer que sistemas linguísticos e semióticos tornam possíveis (podem "gerar") textos que diferem sem limite, mas a amplitude da variação é socialmente delimitada e estruturada, isto é, os sistemas linguísticos e semióticos interagem com as outras estruturas e sistemas sociais. Uma ordem do discurso pode ser mais especificamente vista como uma combinação particular de diferentes discursos, diferentes gêneros e diferentes estilos, que são articulados de modo distintivo.

É importante denotar que a ordem do discurso encerra uma ambiguidade: por um lado, representa uma rede estável e genérica que influencia a produção e reprodução discursiva (denotando seu aspecto estruturante); por outro lado, varia (é uma rede instável) de acordo com o momento específico em que o texto é produzido (ação), propriedade que possibilita a reprodução ou transformação da ordem de discurso hegemônica (FAIRCLOUGH, 2000). Portanto, ela representa, abstratamente, um movimento dialético entre estrutura e ação; é exatamente a estrutura e a ação, ao mesmo tempo, ganhando materialidade a partir do instante em que é incorporada às práticas sociais diversas. Por fim, vale assinalar que uma ordem de discurso estabelece-se a partir de uma permanente relação com os elementos não discursivos das práticas sociais.

Um gênero é formado por características presentes no texto que se associam a determinada atividade social, sinalizando uma forma de agir (como, por exemplo, um texto que cumpre a função de informar, de questionar, de ameaçar, e assim por diante) e interagir dos agentes sociais naquele contexto e diante de um evento social específico (FAIRCLOUGH, 2005b). Magalhães (2001) o conceitua como um conjunto estável de convenções discursivas associadas a uma atividade social, representando-a linguisticamente. Para Pagano (2001), o gênero deve ser pensado como usos da linguagem (ou convenções comunicativas), vinculados a uma comunidade discursiva, para atingir seus objetivos e responder a uma situação social. São exemplos de gênero um bate-papo informal, um poema, um documentário televisivo, um artigo científico, um e-mail, um discurso publicitário, uma comédia, um drama, uma bula de remédio, discursos jurídicos etc. (MAGALHÃES, 2001; PAGANO, 2001). Algumas particularidades devem ser observadas. Um gênero relaciona-se não somente a uma forma textual, mas a atividades específicas da vida social que, por sua vez, refletem e influenciam as práticas sociais (por exemplo, a redação de um artigo científico não é uma atividade literária puramente estética, ligada, somente, ao aspecto formal do texto). Um gênero dificilmente aparece como um tipo puro. A análise de corpora empíricos revela que um gênero é uma combinação de outros (FAIRCLOUGH, 2001a; 2005b; MAGALHÃES, 2001; PAGANO, 2001). Fairclough (2001a) denominou esse fenômeno hibridização de gêneros. Por fim, um sistema/cadeia de gêneros é uma configuração permanentemente sujeita à tensão entre estabilidade e mudança (FAIRCLOUGH, 2001a; MAGALHÃES, 2005; PAGANO, 2001). A possibilidade de combinações de gêneros é definida pelo sistema social/cultural ao qual o texto se vincula. Fairclough (2001b) parte da premissa de que a relação entre o discurso e as outras facetas da vida social não é a-histórica, portanto, em diferentes épocas há diferentes usos sociais do

\footnotetext{
${ }^{24} \mathrm{Na}$ ACD o texto, como um elemento semiótico, presta-se à análise textual e da prática discursiva. Fairclough (2001a) menciona que apesar de, teoricamente, fazer uma distinção entre ambas, na prática (ou seja, na análise do corpus da pesquisa) elas estão entrelaçadas. Uma análise semiótica do texto só está completa quando ambas são investigadas (cf. FAIRCLOUGH, 2005b).
} 
discurso (FAIRCLOUGH, 2001b). Assim, modificações na realidade social sugerem novos gêneros criados por meio de intertextualidade e interdiscursividade.

A intertextualidade se refere às ligações que um texto estabelece com outros, que podem ser denotadas explicitamente ou mescladas ou, ainda, assimiladas ou negadas (FAIRCLOUGH, 2001a). Dessa forma, a análise intertextual significa a identificação de quais textos existentes participam do texto em tela. Portanto, a intertextualidade dota o discurso de historicidade.

Como mencionado, um discurso é um modo de representação da realidade (de pessoas, de processos, de eventos, de objetos etc.), convencionalmente aceito/utilizado por um grupo social. Trata-se, pois, de uma convenção (um senso comum) compartilhada entre os membros de uma comunidade. Dito isso, a análise interdiscursiva consiste na identificação dos discursos presentes (por meio da investigação dos temas abordados e sob a perspectiva de quem) no corpus em investigação e no exame da articulação e desarticulação desses discursos praticada pelos falantes, tendo como guia a identificação dos modos de representação. A interdiscursividade é especialmente importante, pois por meio dela notam-se as articulações do discurso com as práticas sociais e discursivas vinculadas a outras comunidades discursivas ${ }^{25}$.

Um estilo é o modo como as identidades individuais e/ou coletivas manifestam-se no texto (FAIRCLOUGH, 2001a). A análise de estilo implica examinar características textuais em busca de indicativos sobre o modo de ser do enunciador, de posicionar-se na sociedade e de avaliar/julgar o mundo à sua volta. Fairclough (2001a) propõe que o estilo seja pensado a partir de três dimensões: (1) teor - sinaliza a natureza da relação entre os participantes (casual, informal, formal etc.); (2) modo - refere-se à forma como o texto é falado e/ou escrito; (3) retórica - refere-se ao tipo de retórica utilizada, ou seja, a argumentativa, a descritiva etc.

\section{Análise das práticas sociais}

Na ACD, a análise textual e discursiva estabelece uma ponte com a dimensão mais exterior do framework apresentado na Figura 1, a análise das práticas sociais portadoras de ideologias 26 e delimitadoras de hegemonias. Ambas as categorias são centrais na ACD27 e tributárias das ideias de Antonio Gramsci. Três características importantes estão associadas ao primeiro conceito: a ideologia possui existência material nas práticas das instituições (nos empreendimentos humanos, de forma geral), o que abre caminho para compreender as práticas discursivas como formas concretas de ideologia; ela contribui para a constituição dos sujeitos; os aparelhos ideológicos do Estado são locais onde ocorrem as lutas de classe e também marcos delimitadores para tal. Por vezes, a ideologia trabalha tentando disfarçar sua natureza ideológica, tornando-se opaca, naturalizada e automatizada, enfim, adquirindo um status de senso comum (FAIRCLOUGH, 1985; 1995; 2001a), o que dificulta, inclusive, que se reconheça a existência de uma ideologia subjacente à racionalidade decisória humana.

Fairclough $(1985 ; 1995 ; 2001$ ) entende que a ideologia está presente nas estruturas que representam os eventos passados, como nas condições para os eventos atuais; e nos próprios eventos quando reproduzem e transformam as estruturas condicionadoras. Ela própria é o resultado de um trabalho de naturalização e desnaturalização de ideias, que ocorre durante os eventos discursivos. Assim, a ideologia não é uma propriedade da estrutura ou dos eventos ${ }^{28}$, mas das formações ideológicas-discursivas (FID) - uma instituição social é composta por diversas FID ou comunidades de fala ou, ainda, comunidades ideológicas (FAIRCLOUGH, 1985). O linguista insiste em uma postura dialética entre estrutura e indivíduo (por meio dos eventos discursivos), que resulta no estabelecimento de práticas sociais. Acredita que os sujeitos são constrangidos ideologicamente,

\footnotetext{
${ }^{25}$ Fairclough (2001b), por meio da análise de anúncios publicitários de instituições de Ensino Superior na Grã-Bretanha, revela como a interdiscursividade opera através da colonização dessas ações midiáticas pelo discurso da publicidade tradicional de produtos comerciais, aproximando a educação superior de uma commodity. Dessa forma, denuncia uma tendência de mercantilização da Educação Superior que sinaliza uma nova disputa hegemônica no campo em tela. Esse texto de Fairclough é um claro exemplo sobre como as dimensões textual, discursiva e da prática social articulam-se na ACD.

${ }^{26}$ As ideologias são "significações/construções da realidade (o mundo físico, as relações sociais, as identidades sociais) que são construídas em várias dimensões das formas/sentidos das práticas discursivas e que contribuem para a produção, reprodução ou a transformação das relações de dominação" (FAIRCLOUGH, 2001a, p. 117).

${ }^{27} \mathrm{Na} A C D$, as relações de poder presentes na vida social são abordadas por meio da associação entre discurso e ideologia/hegemonia (CHOULIARAKI e FAIRCLOUGH, 1999).

${ }^{28}$ Do contrário - ou seja, se a ideologia for compreendida como uma propriedade da estrutura, como enfatizou Althusser -, concordar-se-ia que os eventos são mera reprodução das estruturas, supervalorizando, assim, a importância das convenções sociais, em detrimento de uma visão dialética e transformadora entre estrutura e evento (ação episódica dos indivíduos). Também não é pertinente concentrar a ideologia nos eventos, pois se estaria conferindo certo caráter atomista a eles, como se estivessem dissociados das convenções sociais e constituíssem uma produção livre (FAIRCLOUGH, 1995; 2001a).
} 
mas também são capazes de exercitar certa autonomia ao criar conexões próprias entre suas práticas e as ideologias às quais são expostos e, conforme o caso, de reestruturar as práticas e as próprias estruturas ideologizantes. $O$ espaço de ação do sujeito dependerá de suas condições socais e das relações de dominação que o cercam.

Como indicado, a ideologia está presente no sentido das palavras, na estrutura/organização de um texto, nas metáforas, na própria coerência do discurso e nas convenções discursivas de que faz uso, entre outros aspectos. $\mathrm{O}$ autor lembra que a riqueza de elementos ideológicos, introduzidos na etapa de produção e interpretação de um texto raramente pode ser representada no próprio texto. Um exemplo disso é a necessidade de, em algumas situações, grafar uma palavra entre aspas, sinalizando para o leitor que ali há outros sentidos possíveis, não explicitados (FAIRCLOUGH, 1995). Daí a importante ligação entre a dimensão ideológica e a análise textual e discursiva.

As ideologias são, portanto, ideias e crenças veiculadas no discurso, constituindo a base para as disputas hegemônicas. A investigação de discursos que se tornam hegemônicos (como e por que eles se tornaram hegemônicos?), gerando uma naturalização de valores, de comportamentos, de saber, de vocabulário etc., é um ponto caro para Fairclough. Por hegemonia deve-se entender: (1) uma liderança e dominação nas esferas econômica, política, cultural e ideológica; (2) o poder sobre a sociedade exercido por determinado grupo social, em um caráter parcial e temporário, constituindo um equilíbrio instável; (3) uma força manifesta na construção de alianças e integração; (4) um foco de luta sobre pontos de instabilidade entre classes/grupos para construir, manter ou romper relações de dominação, que assumem formas econômicas, políticas e ideológicas (FAIRCLOUGH, 2001a).

Assim, existe uma relação direta entre a luta hegemônica e o discurso. Como comentado, Fairclough entende a ordem do discurso (regras discursivas sobre como agir socialmente) como um equilíbrio estável/instável que constitui uma hegemonia e a articulação/rearticulação dessa ordem como um delimitador para a luta hegemônica.

O entendimento do discurso como uma luta hegemônica e, portanto, ideológica, "já que as hegemonias têm dimensões ideológicas" (FAIRCLOUGH, 2001a, p. 126), constitui um meio de investigação sobre as possibilidades de transformação social. Em suma, a ACD tem como meta compreender as condições que (im)possibilitam o surgimento da transformação social por meio da prática discursiva, ou seja, sobre como as (re)articulações do discurso afetam a ordem do discurso vigente - as convenções, os códigos e as estruturas sociais que denotam papéis e ideologias bem definidas. Para o autor, o que dispara tais acontecimentos são as contradições sociais e as lutas estruturais nos níveis institucional e na sociedade. Esse deve ser um dos pilares do trabalho do analista crítico do discurso.

Nesse item, buscamos apresentar um panorama da ACD, detendo-nos em suas principais dimensões analíticas - e em como elas se relacionam - e em suas respectivas categorias conceituais. Essa tarefa foi realizada a partir de uma série de estudos de Fairclough e de autores vinculados ao campo da linguística aplicada, que se dedicam ao estudo teórico e à operacionalização da ACD, A seguir, partindo de exemplos empíricos em contextos organizacionais, ilustramos a aplicação da ACD nos EO brasileiros.

\section{USOS DA ANÁLISE CRÍTICA DO DISCURSO NOS ESTUDOS ORGANIZACIONAIS}

É sensato afirmar, como o fizeram Grant e ledema (2005) e Phillips e Oswick (2012), que o discurso nas organizações, tomado a partir do quadro teórico vinculado à virada linguística, tem despertado crescente interesse no campo internacional de EO. No Brasil, notamos tendência semelhante, encontrando estudos, desde o final da década de 1990 (ALVES, GOMES e SOUZA, 2006), que incorporam distintas vertentes da análise de discurso - assim como também observaram Souza e Carrieri (2014) -, embora ainda haja um enorme espaço a ser explorado. Nesta seção, apresentamos cinco possibilidades de aplicação da ACD em contextos organizacionais no país, sem ter, obviamente, a pretensão de mapear a totalidade da produção nacional sobre o tema.

Um dos aportes significativos da ACD pode ser notado na pesquisa acerca do papel institucional de atores sociais relevantes para a sociedade, utilizando como corpus discursivo relatórios, planos estratégicos, legislação, pronunciamentos, código de ética, entre outras fontes textuais representativas. Um importante eixo de investigação nessa direção é a descoberta de 
marcas textuais que indicam a visão de mundo do enunciador, verificando como essa visão articula-se com práticas sociais de dominação mais amplas. $O$ exemplo a seguir ilustra esse tipo de pesquisa.

O Departamento de Assuntos Econômicos e Sociais das Nações Unidas (DESA) publicou, em 2010, o relatório "Objective and themes of the United Nations Conference on Sustainable Development" sobre desenvolvimento sustentável que, à época, orientaria as ações na Conferência sobre Desenvolvimento Sustentável das Nações Unidas, realizada em 2012, a Rio+20. Analisando um fragmento desse relatório, Melo, Salles e Bellen (2012) concluíram que a Organização das Nações Unidas (ONU) enxerga o papel dos países em desenvolvimento sob dois enfoques: (1) o de vilão da sustentabilidade, sendo responsável por práticas de produção e consumo irresponsáveis; e (2) o de credor de fundos monetários internacionais destinado ao financiamento de ações sustentáveis, o que interessa aos países ricos detentores de capital, pois essa visão transforma as nações em desenvolvimento em credores permanentes - o que significa outra forma de dominação - e dificulta o fortalecimento de capacidades internas com viés autossustentável. Essa expectativa é ancorada pelo discurso ideológico da ONU de cooperação internacional entre os países e de tratamento igualitário entre as nações. No entanto, o que se constatou examinando o corpus em questão é que o discurso da ONU é etnocêntrico, na medida em que os países em desenvolvimento recebem tratamento diferenciado, sofrendo uma pressão internacional para uma atuação mais rigorosa quanto ao desenvolvimento sustentável. Os autores concluem que o relatório para a Rio+20 é um instrumento ideológico que visa a criar/ manter, discursivamente, o domínio hegemônico dos países detentores da liderança econômica e política global. Pela via da ACD, os autores sinalizam que as práticas discursivas de atores institucionais relevantes na sociedade, como a ONU, refletem uma visão unilateral, que favorece a um grupo restrito de países hegemônicos, que termina por delimitar um espaço de ação restrito aos países em desenvolvimento.

Outra importante contribuição sob o mesmo viés é o estudo de Dellagnelo, Salles e Justen (2014) sobre o Plano Nacional de Cultura (PNC). O PNC, aprovado em 2010, é fruto de um debate na sociedade, ao longo de cinco anos, que resultou em uma das principais leis brasileiras que orientam as políticas públicas culturais da década atual. Em 2012, o Governo Federal elaborou metas para estimular a efetiva realização das ações prioritárias previstas no PNC. Portanto, as metas do PNC tornaram-se o verdadeiro conteúdo da política pública cultural brasileira. Uma das diretrizes de ação delineadas pelo Ministério da Cultura (MinC) é pensar "as expressões culturais como determinantes para o desenvolvimento" (DELLAGNELO, SALLES e JUSTEN, 2014, p. 1), ideia que representa um consenso nos fóruns nacional e internacional. As divergências começam a surgir quando se confronta a compreensão de desenvolvimento do MinC com a de outros agentes envolvidos. Percebe-se que a noção de desenvolvimento é basilar na definição dos papéis assumidos pelos atores no campo, argumentam os autores. A partir desse quadro contextual, sucintamente descrito, Dellagnelo, Salles e Justen (2014, p. 2) assim definem a problemática de pesquisa que emerge com a proposição das metas do PNC:

[...] entendendo as metas do Plano Nacional como um importante discurso, o qual reflete uma determinada ideologia, nem sempre explicitamente assumida, destacamos neste trabalho de pesquisa a necessidade de se refletir melhor a respeito da noção de desenvolvimento subjacente às metas que foram definidas para a área da cultura no país.

Para alcançar esse intento, lançam mão da ACD de Fairclough. A análise empreendida revelou características da postura governamental sobre o desenvolvimento da cultura, tais como a excessiva centralização decisória e operatória (denominada perspectiva Estadocêntrica) e a preocupação com o conteúdo simbólico da cultura, denotada pelo incentivo à diversidade de expressões culturais. Creem os autores que a investigação do sentido atribuído à noção de desenvolvimento por meio de sua faceta discursiva cria forças argumentativas capazes de subsidiar a interação entre os agentes envolvidos e o Estado, ampliando as possibilidades de transformação dessas políticas.

Carrieri, Souza e Aguiar (2014) fazem uso da ACD para evidenciar a violência simbólica, verbal e física vivenciada por lésbicas, travestis e transexuais no trabalho e na sociedade em geral. Por meio da análise do corpus discursivo, obtido de entrevistas e anotações de campo, a pesquisa deu voz aos sujeitos ouvidos e evidenciou a existência de grupos heterogêneos abrigados sob uma mesma sigla LGBT: lésbicas, gays, bissexuais e transgêneros.

A análise crítica dos discursos possibilitou o entendimento de como as identidades e as posições dos sujeitos ouvidos são construídas, cotidianamente, a partir da relação conflituosa entre as subjetividades individuais e as práticas discriminatórias 
imbricadas na sociedade. A pesquisa também mostrou como o confronto entre duas posições epistemológicas sobre a realidade opera na vida real - uma visão essencialista, que lê o mundo como construído por verdades naturais, responsáveis pela criação de padrões de normalidade, que admitem pouco espaço para a mudança e a diferença; e uma construtivista da realidade, que compreende o mundo como resultado de uma construção humana, histórica, social e cultural. Há, visivelmente nos discursos dos entrevistados, um conflito identitário denotado pela identidade social e de nascimento.

O estudo realizado por Carrieri, Souza e Aguiar (2014) é um exemplo inspirador sobre como a ACD pode evidenciar as relações de poder, portanto, as ideologias naturalizadas, que sustentam uma miríade de processos de inclusão/exclusão no contexto organizacional, bem como revelar as distintas formas de violência engendradas por tais processos. Por fim, o artigo é uma clara demonstração da transdisciplinaridade proposta por Fairclough (cf. CHOULIARAKI e FAIRCLOUGH, 1999; 2010; FAIRCLOUGH, 2005a; 2005b), ao articular o aporte teórico da análise de discurso com teorias de inspiração crítica ligadas à diversidade no mundo do trabalho e à violência simbólica e interpessoal (física e discursiva). O entendimento de Fairclough é que a ACD deve expandir epistemologicamente os objetos de pesquisa dos cientistas sociais.

Em outro exemplo, Diniz (2012) utiliza a ACD para compreender os discursos gerenciais sobre as mulheres nas matérias da revista Exame, um dos principais veículos de comunicação do segmento de jornalismo econômico e importante formador de opinião na área da administração empresarial. A autora constatou dois discursos mais proeminentes, o feminista desapropriado e o gerencialista reiterado. Ambos apoiam-se no gênero informativo, mas trazem construções discursivas (modos de agir discursivo) distintas.

O primeiro possui um tom denunciativo, sendo composto por fragmentos que retratam as desigualdades de gênero nas organizações, como a sobrecarga de atividades para as mulheres; e possuem um conteúdo avaliativo ou de julgamento sobre aquilo que é certo ou errado, em função de valores que devem ser perseguidos no mundo do trabalho, como a igualdade de condições entre mulheres e homens.

O segundo discurso carrega, também, um conteúdo avaliativo, porém, traz como preocupação central o fato de determinados comportamentos serem desejáveis ou não, à luz do aumento da performance das mulheres e das corporações. Essa narrativa está fortemente pautada pela ideologia da racionalidade instrumental-econômica. Nesse caso, o discurso sobre a feminilidade foi colonizado pelo discurso econômico e mercadológico, que enxerga o ser humano como um provedor de recursos capazes de gerar vantagens ou desvantagens competitivas.

Em seu texto, a autora mostra como ambos os discursos são construídos por modos de agir discursivos, por gêneros, estilos, intertextualidades e vozes distintas, articulando a análise textual e discursiva com as práticas sociais do mundo do trabalho. Revela, ainda, que os discursos não são homogêneos no corpus analisado, sinalizando a ambivalência na construção de ordens discursivas (como mencionado em FAIRCLOUGH 2000; 2001a). Ao final da pesquisa, Diniz (2012) constata que a Exame é um veículo reprodutor das representações sociais sobre a divisão de trabalho entre homem e mulher. Embora haja espaço de mudança para esses papéis em diferentes contextos discursivos, as relações sociais entre homens e mulheres, manifestadas discursivamente na revista, corroboram a manutenção das relações de poder entre os gêneros, assegurando uma forma de dominação ainda patriarcal no universo organizacional.

Diniz (2012) também exemplifica, com propriedade, como a narrativa da Exame faz uso de vozes de pesquisadores(as) e professores(as) no intuito de legitimar as informações veiculadas pela revista. É interessante enfatizar, como sugere a autora, que tais vozes "[de modo geral] vêm apenas corroborar a argumentação colocada pela instância enunciadora, constituindo textos mais monológicos e com pouco espaço para o debate" (DINIZ, 2012, p. 83). Essa observação (res)suscita um importante debate no campo da administração - que deve ser travado continuamente - sobre a responsabilidade ética e social dos pesquisadores ligados à academia brasileira.

Os discursos de Diniz (2012) e de Carrieri, Souza e Aguiar (2014) convergem, na medida em que fazem uso da ACD para denunciar práticas laborais de dominação e de subjugação dos(as) trabalhadores(as) vigentes no contexto organizacional. $O$ entendimento mais claro desse processo é um caminho possível para que eles sejam modificados.

Netto, Brei e Flores-Pereira (2010) analisaram as ações de marketing (campanhas de comunicação veiculadas em outdoor, catálogos, material impresso, vídeos e materiais de internet) de uma empresa de vestuário infantil, a Lilica Ripilica, e, com o auxílio da ACD, evidenciaram a relação entre as práticas textuais/discursivas presentes nas campanhas e o fenômeno social 
da adultização das crianças, isto é, da conversão das crianças em adultos em miniatura, fato que serve como estratégia para impelir os pais e as crianças ao consumo. Os pesquisadores concluem que a marca desperta nas crianças padrões de beleza e de comportamento associados ao mundo adulto, com o objetivo de socializá-las para o mercado de consumo.

Os autores exploram um rico caminho para a aplicação da $A C D$, que é o confronto de vozes a respeito de um mesmo tema. A ACD mostrou que as campanhas investigadas exploram uma imagem de sensualidade nas crianças-modelo, fato que se contrapõe ao discurso "oficinal" de uma produtora de moda da empresa. Outro aspecto evidenciado é que as ações comunicativas da Lilica Ripilica não podem ser pensadas de modo isolado, como se a organização fosse a única responsável pelo fenômeno da adultização infantil. A empresa atua em um contexto social no qual a cultura (o senso comum) admite e, muitas vezes, incentiva esse comportamento em relação à criança, dado que ele também está presente em outros veículos de massa. Advertem os pesquisadores: "O que a Lilica Ripilica faz é utilizar esses valores associados ao senso comum, e que indiscutivelmente são sedutores, em suas estratégias de comunicação" (NETO, BREI e FLORES-PEREIRA, 2010, p. 146). O analista crítico do discurso organizacional deve trazer à tona essas estratégias ideológicas, que passam, frequentemente, como posturas "naturais" da sociedade capitalista. Por fim, pontuam os pesquisadores, que a academia brasileira de marketing deve adotar uma postura mais reflexiva - e menos conformista ou legitimadora - diante dos efeitos do marketing sobre o público infantil.

Tais exemplos ilustram o potencial de sinergia entre a ACD e as pesquisas no campo da administração. Depreendem-se deles observações interessantes: (1) há uma multiplicidade de fontes textuais para a composição do corpus discursivo; (2) uma multiplicidade de temas e perspectivas teóricas podem ser abordados em conjunto com a ACD; (3) uma variedade de categorias conceituais podem ser construídas a partir do legado de Fairclough. Os estudos analisados fazem uso da ACD, mas cada qual a seu modo, revelando um amplo leque de perspectivas teórico-metodológicas possíveis; (4) a ACD será uma possibilidade tanto mais atrativa para a realização de investigações científicas na área se for acoplada a teorias sociais que possibilitem ao pesquisador relacionar o objeto/fenômeno em tela a um quadro ideológico mais amplo. Assim, seu uso se distanciará de uma simples técnica de tratamento e análise de dados discursivos e as pesquisas realizadas tendem a assumir, além de um caráter descritivo-interpretativo, uma postura crítica, contribuindo para o potencial transformador de realidades sociais injustas.

\section{CONSIDERAÇÕES FINAIS}

Partimos, neste artigo, da constatação de uma janela de oportunidade aberta pelos trabalhos de Alvesson e Kärreman (2000a; 2000 b; 2011) para apresentar a abordagem teórica-metodológica da ACD proposta por Norman Fairclough e ilustrar seus diferentes usos nos estudos organizacionais brasileiros. Diante do exposto, destacamos, na sequência, três posicionamentos axiais da ACD tomados como uma das sínteses possíveis acerca das formulações apresentadas.

O primeiro posicionamento axial é a ênfase no discurso como uma prática de significação do mundo, um ato social que opera no cotidiano, mediando as relações entre o indivíduo e seu contexto de vida. O discurso é o elemento semiótico responsável por essa articulação. Ele pode reproduzir a sociedade vigente, perpetuando a realidade, e, ao mesmo tempo, ser o meio para promover mudanças na sociedade. A prática discursiva estabelece, portanto, um grau mínimo de estabilidade cognitiva para tornar possível a vida em sociedade e o reconhecimento de si. Esses efeitos constitutivos do discurso - que recebem o nome, no plano teórico, de (meta)funções da linguagem - podem ser compreendidos como responsáveis por um modo de agir e interagir; por um modo de ler/interpretar a realidade e nomear os fatos, os fenômenos, os sentimentos, de atribuir rótulos, de criar e fazer uso de classificações etc., enfim, de dar forma à realidade a partir de um modo de conhecer, criando uma configuração possível, entre várias elegíveis, de codificação dessa realidade; por último, ao sugerir modos de agir, de enunciar e ser a fonte de esquemas tipificadores e de significações que são compartilhados em uma comunidade de fala, o discurso termina por influenciar a constituição das práticas sociais e dos posicionamentos entre os sujeitos, isto é, de configurar as identidades individuais e coletivas.

O segundo posicionamento em destaque é o entendimento de que as práticas discursivas emergem das lutas de poder, que, necessariamente, na ACD, são lutas ideológicas. As ações discursivas, como um tipo de prática social resultante de uma permanente negociação com o mundo, estão atreladas a ideologias que parecem opacas, ou seja, via de regra, parecem invisíveis 
aos envolvidos no processo comunicativo. Essas ideologias assumem a forma de senso comum, de verdades naturalizadas. Ensina Fairclough que a tentativa de manter a opacidade ideológica dos discursos é, ela própria, uma forma de dominação.

O último aspecto que elegemos para recordar encontra-se, naturalmente, na essência da ACD enquanto abordagem ligada à linguística aplicada. Trata-se da relação entre texto, discurso e mundo. As funções sociais da linguagem e sua natureza ideológica são refletidas nos textos. Um texto revela-se, pois, um dado social não desprezível aos cientistas sociais. $\mathrm{O}$ quadro tridimensional de Fairclough busca combinar os três posicionamentos axiais expostos simplificadamente nestas considerações finais, mas que foram detalhados ao longo do artigo. Um trabalho de pesquisa com a ACD pode prescindir de fazer referência direta ao modo tridimensional tal como proposto originalmente. No entanto, parece-nos pouco adequado, à luz do legado intelectual de Fairclough, que um analista crítico do discurso não trabalhe com a articulação das dimensões texto, prática discursiva (ou ordem do discurso ou, simplesmente, discurso) e práticas sociais (ou realidade social).

A partir dessa breve retrospectiva teórica, duas reflexões sobre as implicações da ACD nos EO são propostas para estimular as pesquisas futuras sobre o discurso nas organizações.

\section{As organizações sob a ótica da análise crítica do discurso: um fenômeno político, multifacetado e vivo}

A proposta neste tópico é repensar o objeto de estudo do pesquisador organizacional - as organizações e o organizar -, a partir da analítica de Fairclough. Seguindo Santos (1996, p. 16), entendemos que o "o corpus de uma disciplina é subordinado ao objeto, e não o contrário". As ideias expostas no artigo dão subsídio para se enxergar as organizações e a prática da gestão sob a ótica da linguagem, para além de seu entendimento meramente instrumental, como alertaram Honório e Mattos (2010, p. 23): "é intrigante verificar, não apenas a pouca influência da recente pesquisa sobre a linguagem nos estudos organizacionais, mas também a redução da palavra, pela teoria administrativa, a aspectos instrumentais a serviço da comunicação".

No escopo da ACD, as organizações podem ser vistas como construções discursivas ${ }^{29}$ operando em um contexto ideológico, histórico e cultural, com variável grau de estabilidade e em contínua relação com a realidade instaurada. Fairclough (1985; 1995; 2005a) sintetiza essas características afirmando que as organizações são FID, e cada uma delas constitui uma comunidade de fala e de imagens, com suas próprias normas discursivas e ideológicas, conceitua o autor. Os sujeitos organizacionais são constituídos (e constituem) pelas regras da FID e uma característica importante dessa comunidade é sua capacidade de naturalizar ideologias e definir modos de vivenciar a realidade (práticas de tipificação e de sentido).

Objetivamente, o fato de compreender as organizações como FID evidencia um olhar sobre a organização como:

- Um fenômeno político: a organização é o que emerge da ação política entre os sujeitos sociais, no sentido em que Hanna Arendt conceituou o termo política ${ }^{30}$. Entender a organização como um campo discursivo implica imaginá-la como uma arena de interesses e valores conflitantes (espaço de mediação e de contestação), manifestados por atos discursivos, aspecto ignorado, muitas vezes, nas pesquisas acadêmicas em administração. Engajar-se em práticas discursivas (escritas, faladas, visuais etc.) é um modo de agir politicamente, isto é, de disputar a hegemonia por meio da determinação de conceitos e ações e pela ocupação de papéis-chave na organização, que asseguram o direito de produzir novos discursos (PHILLIPS, SEWELL e JAYNES, 2007; PUTNAM, PHILLIPS e CHAPMAN, 2004);

- Um arranjo de diferenças: pensar a organização como diferença é compreendê-la como um ente em constante ambiguidade discursiva e racional (COOPER, 1990). Nessa perspectiva, a organização é menos representada por um estado ordenado de objetivos e ideias e mais por um estado de negociação, conflito, dissenso, imprecisão, relações de poder e, sobretudo, por uma relativa tolerância à diversidade;

- Um fenômeno em constante mutação (um fenômeno vivo): propõe-se uma visão das organizações como elas acontecem (MIETTINEN, SAMRA-FREDERICKS e YANOW, 2010; SANTOS e SILVEIRA, 2015; SCHATZKI, 2006), isto é, das organizações como uma multiplicidade de processos (multiníveis) no "aqui e agora", ligados a uma história - lógica que sugere fluidez, estados de alternância entre estabilidade-instabilidade e desconstrução/construção

\footnotetext{
${ }^{29}$ Ao refletir sobre o que são os estudos organizacionais, Clegg e Hardy (2010, p. 32) assim se expressaram: "[os estudos organizacionais são] uma série de conversações, em particular aquelas dos pesquisadores dessa área que ajudam a constituir as organizações por meio de termos derivados de paradigmas, métodos e suposições, todos decorrentes de conversações prévias".

${ }^{30}$ Para a filósofa, fazer política não é um atributo natural do ser humano. "A política surge no entre-os-homens; portanto, totalmente fora dos homens. Por conseguinte, não existe nenhuma substância política original. A política surge no intraespaço e se estabelece como relação" (ARENDT, 2012, p. 23).
} 
cotidiana. Essa perspectiva é mais adequada para capturar as singularidades e entender os distintos modos de organizar (as práticas organizativas) que, de fato, retratam a vivência diária organizacional. Cabe pontuar, seguindo Cavalcanti e Alcadipani (2013, p. 562), que pensar dessa forma "não pressupõe um possível 'enfraquecimento'” ou distanciamento do objeto de estudo da administração, mas significa caminhar em direção contrária, optando por buscar subsídios conceituais que possibilitem compreender a natureza mutante da realidade social.

De modo complementar, enxergar as organizações como FID evidencia, também, a relação entre conhecimento administrativo, ideologia e discurso, trazendo à tona o poder e a hegemonia como categorias conceituais que perpassam os fenômenos organizacionais, aspecto desenvolvido no próximo item.

Acreditamos que a reflexão sobre o objeto epistêmico da administração deve ser acompanhada por uma imaginação metodológica. Teoria e método, apesar de sua existência autônoma, devem ser pensados em conjunto: "Falar em objeto sem falar em método pode ser apenas o anúncio de um problema, sem, todavia, enunciá-lo" (SANTOS, 1996, p. 16). A proposta de Norman Fairclough representa, ao mesmo tempo, uma reflexão onto-epistemológica sobre as organizações (pautada em uma ontologia social dialética entre agência/estrutura), conjugada com um esforço metodológico de inclinação prática (operacional), que termina por apontar possibilidades concretas para se estudar os fenômenos organizacionais em sua faceta discursiva. Para ilustrar como a ACD pode cumprir o papel de promover um "ponto de entrada" discursivo para as problematizações pertinentes à agenda do pesquisador em organizações, Fairclough (2005a) apresenta quatro temas passíveis de ser explorados:

- Emergência dos discursos: nada vem do nada; novos discursos surgem por meio de relações com velhos discursos. Assim, como ocorre a emergência de novos discursos? Como eles são articulados com os elementos dos discursos existentes? Alguns autores denominam esse processo bricolagem;

- Hegemonia dos discursos: quais discursos se tornaram hegemônicos, ou seja, quais se acoplaram melhor à realidade organizacional? Por que esses discursos (e não outros) se tornaram hegemônicos?

- Recontextualização discursiva: é um processo de colonização/apropriação dialética, na medida em que as organizações são colonizadas por um discurso externo, mas elas atualizam ativamente tal discurso, dando a ele uma forma particular, que pode produzir resultados diferentes do discurso original. Cabe perguntar: como ocorre a incorporação de determinado(s) discurso(s) na organização? Como ocorre a disseminação desse(s) discurso(s) entre as organizações e stakeholders? Como ocorre a disseminação do(s) discurso(s) hegemônico(s) entre as escalas local, nacional e internacional?

- Operacionalização discursiva: cabe questionar se os discursos modificaram o modo de agir (as práticas), a identidade e trouxeram à tona novos objetos e propriedades do mundo físico (questão espacial, por exemplo) que eram negligenciadas; como esses processos ocorreram (ou não ocorreram)?

Fairclough (2005a) insiste em afirmar que tal ordenamento de ideias tem a função didática de apontar o potencial da ACD para os EO, mas não deve ser assimilado pela comunidade acadêmica como uma prescrição. Sua fala ressalta a necessidade do pesquisador criar seu próprio roteiro analítico, a partir de suas bases teóricas e do problema que almeja investigar.

Por fim, Chouliaraki e Fairclough (2010) fazem um importante alerta sobre a aplicação da ACD. Embora as organizações devam ser pensadas como objetos discursivos, é necessário manter o foco não somente nos discursos, "mas nas relações entre discurso e outros elementos sociais" (CHOULIARAKI e FAIRCLOUGH, 2010, p. 1215), a fim de evitar uma falácia epistemológica - associada a certos tipos de AD apoiadas em um construcionismo social radical - que crê na organização como sendo constituída integralmente por eventos discursivos (ações episódicas dos indivíduos), obliterando as lutas dialéticas entre as estruturas sociais (formações ideológicas-discursivas naturalizadas) e os eventos/processos discursivos atuais.

\section{A naturalização do conhecimento administrativo}

Desde a década de 1980 no campo dos EO, há um crescente movimento na direção de denunciar o processo de naturalização do conhecimento administrativo disseminado por meio das práticas de ensino nos cursos de graduação e pós-graduação, das práticas de consultoria, dos discursos institucionais de grandes empresas e governos, entre outros. Entende-se por naturalização (do ensino) da gestão a noção de que as teorias administrativas, comuns, por exemplo, nos manuais didáticos da disciplina, são assimiladas como conhecimentos (expressos em atos discursivos) puros e neutros, isto é, isentos de uma fundamentação política e ideológica, e universais, ou seja, representam um tipo de saber pouco dependente do contexto social em que será aplicado (ALCADIPANI e CALDAS, 2012; ALCADIPANI, KHAN, GANTMAN et al., 2012; DAVEL e ALCADIPANI, 
2003; FRENKEL e SHENHAV, 2006). Assim, um tipo específico de discurso sobre a gestão adquiriu um status hegemônico e grande parte das conversações na área ocorre sob essa perspectiva, de modo que a produção de saber e de sentido é realizada assumindo esse pensamento como uma verdade. Uma manifestação desse saber reificado encontra-se no fato das práticas gerenciais vinculadas ao mainstream da administração refletirem o triunfo da técnica e da racionalidade sobre as individualidades humanas percebidas como difíceis de ser controladas (REED, 2010). Nessa dinâmica histórica, fundada sob o auspício da ciência moderna ${ }^{31}$, o discurso sobre a gestão/administração (ou business/management) foi, paulatinamente, configurando a noção de organização como uma forma hierárquica, controlada por poucos, capaz de assegurar a passagem de uma sociedade desorganizada para um mundo organizado e civilizado (TOLEDO e SILVA, 2014).

Como pontua Fairclough, a naturalização confere opacidade à ideologia e os indivíduos, muitas vezes, sequer percebem o jogo de poder envolvido nos discursos reificados. A ACD pode auxiliar a desvendar a motivação ideológica presente nos projetos organizacionais e a seção "Usos da análise crítica do discurso nos estudos organizacionais" demonstra essa via político-epistemológica. Por exemplo, a ACD é um caminho factível para analisar a construção discursiva dos principais manuais didáticos na área, respondendo a questionamentos do tipo: quem domina as condições sociais de produção do discurso didático sobre administração? Quais vozes são evidenciadas nesse discurso e quais são silenciadas? Qual é a contribuição do conhecimento didático para a efetiva constituição do empoderamento das minorias sociais? O levantamento dessas questões - e de tantas outras - forneceriam subsídios para um debate mais profundo sobre os efeitos das práticas gerenciais na vida das pessoas e na construção de uma sociedade mais justa.

Resumidamente, acreditamos que, ao enfatizar a articulação entre fenômenos/fatos sociais e o contexto mais amplo em que ocorrem, a ACD possibilita uma interpretação crítica dos fatos organizacionais - descolada dos saberes reificados sobre a gestão -, e uma reconexão da administração às problemáticas da sociedade contemporânea. Como afirma Aktouf (1996), é necessário pensar nos compromissos sociais, políticos e humanitários da gestão, dado que as empresas estão envolvidas na causação de uma série de problemas como poluição ambiental, excesso de lixo, destruição das culturais locais, conflitos bélicos, entre outros.

\section{Desafios e orientações em torno da análise crítica do discurso}

O conteúdo desenvolvido neste artigo constitui, naturalmente, uma primeira fonte de desafios e orientações acerca da ACD. Acrescentemos mais alguns, para finalizar. $\mathrm{O}$ analista crítico pode concentrar-se em identificar as diversas FID constituintes da organização - ou do grupo social investigado -, enfocando a articulação dos discursos de cada uma dessas comunidades. Além de concentrar-se na diversidade entre os grupos e em sua relação no momento presente, um interessante caminho é focar como essas diferenças são engendradas e atualizadas no tempo/espaço, trazendo à tona a história dos sujeitos e das práticas cotidianas. Cabe, ainda, confrontar os discursos com as práticas sociais não discursivas, atentando para as contradições e convergências.

A composição do corpus discursivo também é um elemento vital. Análises longitudinais tendem a enriquecer trabalhos com a ACD, bem como a escolha de um corpus que reflita o contexto real de investigação. Recomenda-se atenção, a fim de que o corpus não comprometa, logo de partida, o objetivo da pesquisa.

Nós, pesquisadores ligados à ciência administrativa e não ao campo linguístico, precisamos explorar melhor os elementos conceituais da ACD, para que possamos evoluir, constantemente, na realização de análises textuais e da prática discursiva (análise de gêneros, intertextualidade, interdiscursividade, estilo etc.) mais detalhadas. A aproximação entre ambos os campos é um desafio para nossa área. Especialmente em Fairclough (2005b), o autor afirma que, talvez, a grande divisão no campo da AD seja entre os estudos que abrem mão de análises textuais e discursivas detalhadas e aqueles, naturalmente, que as consideram imprescindíveis. A ACD pertence ao segundo grupo, completa o autor.

Por fim, espelhando-se em Diniz (2012), consideramos que utilizar a ACD para criticar as práticas organizativas não implica abandonar o projeto de interferir na forma de agir das organizações em benefício de um empoderamento da minoria e do estabelecimento de práticas administrativas que favoreçam o bem comum. Pelo contrário, a proposta é criar subsídios para pensar em modos mais equânimes de ação por parte das organizações, instituições e grupos sociais em geral.

\footnotetext{
${ }^{31}$ Entre as várias características que se acomodam no conceito de ciência moderna, destacamos, neste momento, o princípio de que a realidade é fundamentada em regularidades e regida por leis independentes do sujeito que conhece (FERREIRA, CALVOSO e GONZALES, 2002). Em outros termos, a ciência moderna apoia-se na busca por verdades universais e a-históricas contidas nos fatos. Naturalmente, a racionalidade instrumental se acopla perfeitamente a esse projeto, como formulou Habermas (1968). O filósofo discorre sobre a impossibilidade de desenvolver um conhecimento científico puro (ou neutro), pretensão que o autor denomina ilusão objetivista, apontando, assim, a inseparabilidade entre conhecimento e interesse/ideologia e, portanto, entre a racionalidade instrumental e a ideologia capitalista.
} 


\section{REFERÊNCIAS}

AKTOUF, O. Traditional management and beyond: a matter of renewal. Montreal: Morin, 1996.

ALCADIPANI, R. et al. Southern voices in management and organization knowledge. Organization, v. 19, n. 2, p. 131-143, 2012.

ALCADIPANI, R.; CALDAS, M. P. Americanizing Brazilian management. Critical Perspectives on International Business, v. 8, n. 1, p. 37-55, 2012.

ALVES, M. A.; GOMES, M. V. P.; SOUZA, C. M. L. Análise do discurso no Brasil: será ela crítica? In: ENCONTRO DA ASSOCIAÇÃO NACIONAL DE PÓS-GRADUAÇÃO E PESQUISA EM ADMINISTRAÇÃO, 30., 2006, Salvador. Anais... Salvador: Anpad, 2006, p. 1-17.

ALVESSON, M.; KÄRREMAN, D. Taking the linguistic turn in organizational research: challenges, responses, consequences. The Journal of Applied Behavioral Science, v. 36, n. 2, p. 136-158, 2000a.

ALVESSON, M.; KÄRREMAN, D. Varieties of discourse: on the study of organizations through discourse analysis. Human Relations, v. 53, n. 9, p. 1125-1149, 2000b.

ALVESSON, M.; KÄRREMAN, D. Decolonializing discourse: critical reflections on organizational discourse analysis. Human Relations, v. 64, n. 9, p. 1121-1146, 2011.

ARENDT, H. O que é política. 10. ed. Rio de Janeiro: Bertrand Brasil, 2012.

BRANDÃO, H. H. N. A análise do discurso. In: BRANDÃO, H. H. N. Introdução à análise do discurso. Campinas, SP: Ed. Unicamp, 2002. 15-42 p.

CARRIERI, A. P.; SOUZA, E. M.; AGUIAR, A. R. C. Trabalho, violência e sexualidade: estudo de lésbicas, travestis e transexuais. Revista de Administração Contemporânea, v. 18, n. 1, p. 78-95, 2014.

CAVALCANTI, M. F. R.; ALCADIPANI, R. Organizações como processos e teoria ator-rede: a contribuição de John Law para os estudos organizacionais. Cad. EBAPE.BR, v. 11, n. 4, p. 556-568, 2013.

CHOULIARAKI, L.; FAIRCLOUGH, N. Discourse in late modernity: rethinking critical discourse analysis. Edinburgh: Edinburgh University Press, 1999.

CHOULIARAKI, L.; FAIRCLOUGH, N. Critical discourse analysis in organizational studies: towards an integrationist methodology. Journal of Management Studies, v. 47, n. 6, p. 1213-1218, 2010.

CLEGG, S. R.; HARDY, C. Introdução: organização e estudos organizacionais. In: CLEGG, S. R.; HARDY, C.; NORD, W. R. (Org.). Handbook de estudos organizacionais. v. 1. São Paulo: Atlas, 2010. 29-58 p.

COOPER, R. Organization/disorganization. In: HASSARD, J.; PYM, D. (Org.). The theory and philosophy of organizations: critical issues and new perspectives. New York: Routledge, 1990. 167-197 p.

CORTEZ, M. T. O discurso terapêutico e a análise crítica do discurso. 231 f. Dissertação (Mestrado em Estudos Linguísticos) - Faculdade de Letras, Universidade Federal de Minas Gerais, Belo Horizonte, 2003.

CUNHA, R. B. A relação significante e significado em Saussure. ReVEL, n. 2, p. 1-14, 2008.
DAVEL, E.; ALCADIPANI, R. Estudos críticos em administração: a produção científica brasileira nos anos 1990. Revista de Administração de Empresas, v. 43, n. 4, p. 72-85, 2003.

DEETZ, S. A. Reclaiming the legacy of the linguistic turn. Organization, v. 10, n. 3, p. 421-429, 2003.

DELLAGNELO, E. H. L.; SALLES, H. K.; JUSTEN, C. E. A ideia de desenvolvimento nas metas do plano nacional de cultura, uma discussão a partir da análise crítica do discurso. In: CONGRESSO BRASILEIRO DE ESTUDOS ORGANIZACIONAIS, 2., 2014, Uberlândia. Anais... Uberlândia, MG: Sociedade Brasileira de Estudos Organizacionais, 2014. p. 1-8.

DERRIDA, J. Implicações: entrevista a Henri Ronse. In: DERRIDA, J. Posições. Belo Horizonte: Autêntica, 2001a. 9-22 p.

DERRIDA, J. Semiologia e gramatologia: entrevista a Julia Kristeva. In: DERRIDA, J. Posições. Belo Horizonte: Autêntica, 2001b. 9-22 p.

DINIZ, A. P. R. Mulheres gerenciáveis? Uma análise dos discursos sobre as mulheres na revista Exame. $147 \mathrm{f}$. Dissertação (Mestrado em Administração) - Centro de Pós-Graduação e Pesquisa em Administração, Universidade Federal de Minas Gerais, Belo Horizonte, 2012.

FAIRCLOUGH, N. L. Critical and descriptive goals in discourse analysis. Journal of Pragmatics, v. 9, p. 739-763, 1985.

FAIRCLOUGH, N. L. Language, ideology and power. In: FAIRCLOUGH, N. L. Critical discourse analysis: the critical study of language. Edinburg: Pearson, 1995. 21-84 p.

FAIRCLOUGH, N. L. Discourse, social theory, and social research: the discourse of welfare reform. Journal of Sociolinguistics, v. 4, n. 2, p. 163-195, 2000.

FAIRCLOUGH, N. L. Teoria social do discurso. Brasília, DF: Ed. UnB, 2001a.

FAIRCLOUGH, N. L. A análise crítica do discurso e a mercantilização do discurso público: as universidades. In: MAGALHÃES, C. (Org.). Reflexões sobre a análise crítica do discurso. Belo Horizonte: Ed. UFMG, 2001b. 31-81 p.

FAIRCLOUGH, N. L. Peripheral vision: discourse analysis in organization studies - the case for critical realism. Organization Studies, v. 26 , n. 6 , p. 915-939, 2005a

FAIRCLOUGH, N. L. Critical discourse analysis in transdisciplinary research. In: WODAK, R.; CHILTON, P. A. (Org.). A new agenda in (critical) discourse analysis: theory, methodology, and interdisciplinary. Amsterdam/Philadelphia: John Benjamins, 2005b. 53-70 p.

FERREIRA, R. F.; CALVOSO, G. G.; GONZALES, C. B. L. Caminhos da pesquisa e a contemporaneidade. Psicologia: Reflexão e Crítica, v. 15, n. 2, p. 243-250, 2002.

FRENKEL, M.; SHENHAV, Y. From binarism back to hybridity: a postcolonial reading of management and organization studies. Organization Studies, v. 27, n. 6, p. 855-876, 2006.

FOUCAULT, M. Microfísica do poder. Rio de Janeiro: Graal, 1992.

FOWLER, R. Sobre a linguística crítica. Linguagem em (Dis)curso, v. 4, n. esp., p. 207-222, 2004. 
GRANT, D.; IEDEMA, R. Discourse analysis and the study of organizations. Text, v. 25, n. 2, p. 37-66, 2005.

HABERMAS, J. Técnica e ciência como ideologia. Lisboa: Ed. 70, 1968.

HONÓRIO, J. B.; MATTOS, P. L. C. L. Papéis organizacionais: o que a pragmática da linguagem nos leva a pensar. Revista Alcance, v. 17, n. 1, p. 22-33, 2010.

MAGALHÃES, C. M. A análise crítica do discurso enquanto teoria e método de estudo. In: MAGALHÃES, C. (Org.). Reflexões sobre a análise crítica do discurso. Belo Horizonte: Ed. UFMG, 2001. 15-30 p.

MAGALHÃES, I. Introdução: a análise de discurso crítica. D.E.L.T.A., v. 21, p. 1-9, 2005.

MARTIN, J. R. Analysing genre: functional parameters. In: CHRISTIE, F.; MARTIN, J. R. (Org.). Genre and institutions: social processes in the workplace and school. London: Continuum, 1997. 3-39 p.

MELO, P. T. N. B.; SALLES, H. K.; BELLEN, H. M. V. Quadro institucional para o desenvolvimento sustentável: o papel dos países em desenvolvimento com base na análise crítica do discurso da Rio+20. Cad. EBAPE.BR, v. 10, n. 3, p. 701-720, 2012.

MIETTINEN, R.; SAMRA-FREDERICKS, D.; YANOW, D. Re-turn to practice: an introductory essay. Organization Studies, v. 30, n. 12, p. 1309-1327, 2010.

NETTO, C. F. S.; BREI, V. A.; FLORES-PEREIRA, M. T. O fim da infância? As ações de marketing e a "adultização" do consumidor infantil. Revista de Administração Mackenzie, v. 11, n. 5, p. 129-150, 2010.

PAGANO, A. S. Gêneros híbridos. In: MAGALHÃES, C. (Org.). Reflexões sobre a análise crítica do discurso. Belo Horizonte: Ed. UFMG, 2001. 83-119 $p$

PHILLIPS, N.; OSWICK, C. Organizational discourse: domains, debates and directions. The Academy of Management Annals, v. 6, n. 1, p. 435-481, 2012.

PHILLIPS, N.; SEWELL, G.; JAYNES, S. Applying critical discourse analysis in strategic management research. Organizational Research Methods, v. 11, n. 4, p. 770-789, 2007.

PUTNAM, L. L.; PHILLIPS, N.; CHAPMAN, P. Metáforas da comunicação e da organização. In: CLEGG, S. R.; HARDY, C.; NORD, W. R. (Org.). Handbook de estudos organizacionais. São Paulo: Atlas, 2004. v. 3, p. 77-125

RECKWITZ, A. Toward a theory of social practices: a development in culturalist theorizing. European Journal of Social Theory, v. 5, n. 2, p. 243-263, 2002.
REED, M. I. Teorização organizacional: um campo historicamente contestado. In: CLEGG, S. R.; HARDY, C.; NORD, W. R. (Org.). Handbook de estudos organizacionais. v. 1. São Paulo: Atlas, 2010. 61-97 p.

RESENDE, V. M.; RAMALHO, V. C. V. S. Análise de discurso crítica, do modelo tridimensional à articulação entre práticas: implicações teórico-metodológicas. Linguagem em (Dis)curso, v. 5, n. 1, p. 185207, 2004.

RODRIGUES, M. S.; DELLAGNELO, E. H. L. Poder, discurso e mercado: reflexões a respeito dos limites e potencialidades da análise do discurso. In: COLÓQUIO INTERNACIONAL DE EPISTEMOLOGIA E SOCIOLOGIA DA CIÊNCIA DA ADMINISTRAÇÃO, 2., 2012, Florianópolis. Anais... Florianópolis: UFSC, 2012. p. 1-16. Disponível em: <http:// coloquioepistemologia.com.br/site/wp-content/uploads/2013/05/ ANE108.pdf>. Acesso em: 4 jul. 2014.

RODRIGUES-JÚNIOR, A. S. Análise crítica do discurso: modismo, teoria ou método? Revista Brasileira de Linguística Aplicada, v. 9, n. 1, p. 99-132, 2009.

SANTOS, L. L. S.; SILVEIRA, R. A. Por uma epistemologia das práticas organizacionais: a contribuição de Theodore Schatzki. Organizações \& Sociedade, v. 22, n. 72, p. 79-98, 2015.

SANTOS, M. A natureza do espaço: tempo e técnica, razão e emoção. São Paulo: Hucitec, 1996.

SCHATZKI, T. R. Wittgenstein and the social context of an individual life. History of the Human Sciences, v. 13, n. 1, p. 93-107, 2000.

SCHATZKI, T. R. Peripheral vision: the sites of organizations. Organization Studies, v. 26, n. 3, p. 465-484, 2005.

SCHATZKI, T. R. On organizations as they happen. Organization Studies, v. 27, n. 12, p. 1863-1873, 2006.

SOUZA, M. M. P.; CARRIERI, A. P. A análise do discurso em estudos organizacionais. In: SOUZA, E. M. (Org.). Metodologias e analíticas qualitativas em pesquisa organizacional: uma abordagem teórico-conceitual. Vitória: Ed. UFES, 2014. 13-38 p.

TOLEDO, D.; SILVA, E. R. Ensaio sobre o duplo organização-organizar. In: COLÓQUIO INTERNACIONAL DE EPISTEMOLOGIA E SOCIOLOGIA DA CIÊNCIA DA ADMINISTRAÇÃO, 4., 2014, Florianópolis. Anais... Florianópolis: UFSC, 2014. 1-19 p. Disponível em: <http://coloquioepistemologia.com.br/site/wp-content/uploads/2014/03/ANE106. pdf>. Acesso em: 4 jul. 2014.

WODAK, R. Do que trata a ACD: um resumo de sua história, conceitos importantes e seus desenvolvimentos. Linguagem em (Dis)curso, $v$. 4, n. esp., p. 223-243, 2004.

Everton Rodrigues da Silva

Doutorando em Administração pelo Cepead/UFMG; Professor assistente da Universidade Federal de Alfenas. E-mail: everton.silva@unifal-mg.edu.br

Carlos Alberto Gonçalves

Doutor em Administração pela Universidade de São Paulo (USP); Professor pesquisador na Universidade Federal de Minas Gerais (CEPEAD) e na Universidade FUMEC. E-mail: carlos@face.ufmg.br 